\title{
Finite Element Analysis of the Magnetic Field Distribution in a Magnetic Abrasive Finishing Station and its Impact on the Effects of Finishing Stainless Steel AISI 304L
}

\author{
Michał Marczak * and Józef Zawora \\ Institute of Manufacturing Technology, Warsaw University of Technology, 00-661 Warsaw, Poland; \\ jzawora@meil.pw.edu.pl \\ * Correspondence: michal.marczak@pw.edu.pl; Tel.: +48-22-234-5208
}

check for updates

Citation: Marczak, M.; Zawora, J.

Finite Element Analysis of the Magnetic Field Distribution in a Magnetic Abrasive Finishing Station and its Impact on the Effects of Finishing Stainless Steel AISI 304L. Metals 2021, 11, 194. https:/ / doi.org/10.3390/met11020194

Academic Editor: Jordi Sort Viñas Received: 31 October 2020

Accepted: 14 January 2021

Published: 21 January 2021

Publisher's Note: MDPI stays neutral with regard to jurisdictional claims in published maps and institutional affiliations.

Copyright: (c) 2021 by the authors. Licensee MDPI, Basel, Switzerland. This article is an open access article distributed under the terms and conditions of the Creative Commons Attribution (CC BY) license (https:// creativecommons.org/licenses/by/ $4.0 /)$.

\begin{abstract}
In this article, we present a numerical model of a magnetic abrasive finishing station, which was analyzed using the finite element method (FEM). The obtained results were compared with the real values measured on an experimental station of our own design. The prepared station had the option of adjusting the magnetic flux density inside the machining gap, the width of which could be changed from 10 to $30 \mathrm{~mm}$. The maximum value of the magnetic flux density inside the air gap was $0.8 \mathrm{~T}$. The real distribution of magnetic flux density in the finishing area was also analyzed. A design of experiment was carried out with the following variables: abrasive grain concentration, width of the machining gap, and process duration. The results are presented in the form of regression equations and characteristics for selected roughness parameters.
\end{abstract}

Keywords: magnetic abrasive finishing; magnetic field distribution; flexible abrasive finishing; surface roughness; abrasive finishing of AISI 304L

\section{Introduction}

The development of industry triggers demand for finishing technologies to produce high-quality products in terms of their mechanical and physical properties. An aspect that affects both features is the structure of the surface layer, which determines its quality. Proper preparation of the surface in terms of roughness, shape accuracy, and stress distribution significantly affects the functional properties of products, such as tightness, corrosion resistance, electrical conductivity, adhesion level, fatigue, and abrasive wear [1-3].

Magnetic abrasive finishing is an unconventional manufacturing technique that makes it possible to significantly reduce surface roughness [4,5]. However, in order to achieve the desired effects, it is important to design appropriate finishing kinematics [6-9].

Modelling plays the key role in designing process. You can find interesting works concerning finite element method (FEM) magnetic field modelling, an example of which is Kariganaur, Kumar and Arun [10], who present axisymmetric magnetorheological damper model and its analysis using ANSYS finite element (FE) to simulate a distribution of magnetic field in the fluid flow region.

Mosavat and Rahimi [11] used the combined algorithm of the finite element method (FEM) and a smoothed particle hydrodynamics (SPH) model to simulate the surface polishing of silicon wafers with the magnetic abrasive finishing (MAF) process.

Kum et al. [12] proposed the material removal rate model of magnetic-field-assisted finishing process (MFAF) with analysis of the double-magnet magnetic flux density distribution.

Another theoretical model of material removal rate was developed by Yuewu Gao et al. [13]. It takes into account the indentation depth, grinding trajectory, number of active hard abrasives and the simulation of magnetic flux density for three dimensional model.

The effects of magnetic-abrasive machining depend on many physical and chemical factors. These include the force acting on individual abrasive grains (Figure 1). 


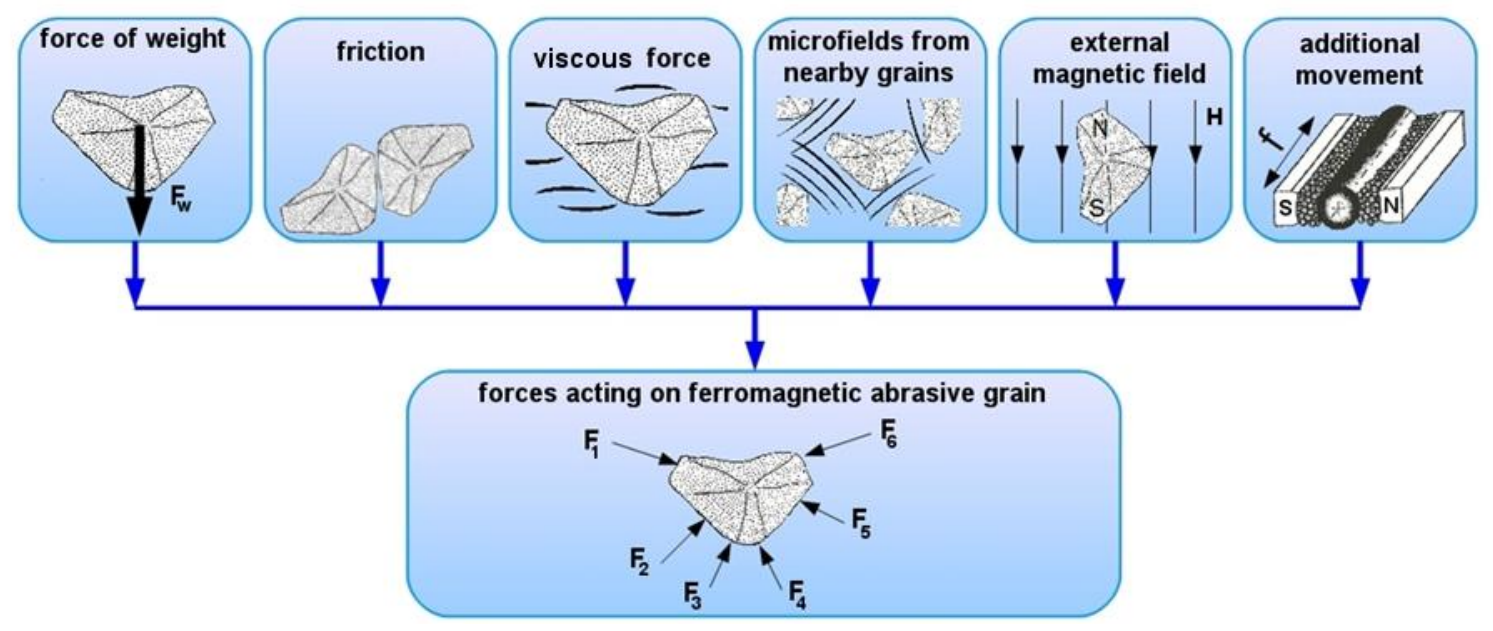

Figure 1. Factors determining force acting on ferromagnetic abrasive grains.

One important aspect of magnetic abrasive finishing is the generation of high magnetic flux density in the finishing area, which significantly affects the force acting on individual ferromagnetic abrasive grains and helps improve the finishing process [14].

The magnetic field can be formed using induction coils [15] or permanent magnets [16]. Thanks to great progress in the production technology of permanent magnets with increasingly better performance parameters, the number of devices where they can be used cost-effectively is growing.

The great coercion of the currently manufactured magnets makes it possible to develop new magnetic abrasive finishing tools characterized by small dimensions, which enable work in rotary motion. Classical solutions using coil systems are characterized by high mass, difficulty in providing a power supply in rotary motion, and considerable dimensions [17].

In order to increase the magnetic flux density in the machining gap and to minimize the magnetic fringe field, a magnetic circuit with the lowest possible magnetic resistance should be used. A special construction of the experiment station that enables reduction of the magnetic fringe field creates wider possibilities for industrial applications without the risk of magnetizing other tools and measuring instruments located in the vicinity of the station.

In this study, a stainless steel AISI 304L plate material (Mahabali, Mumbai, India) was machined by a flexible magnetic abrasive brush, according to the rules of a design of experiments (DOE) with different parameters (concentration of abrasive grains, width of machining gap and time process). The evaluation of the design of experiment was carried out and then the 2D and 3D surface roughness, flatness, loss of sample mass and tool marks were analyzed. In addition, the effects of magnetic flux distribution on the shape of the magnetic abrasive brush were studied in this research.

The purpose of this research is to investigate whether the parameters of the surface layer of AISI 304L stainless steel will be improved within the assumed range of machining parameters, so that precision increases and better surface quality of manufacturing elements is achieved.

The innovative approach in the presented paper consists of the design and execution of an experimental station that minimizes magnetic fringe field and a detailed and comprehensive analysis of MAFP with the use of modern solid ferromagnetic Fe-TiC abrasive particles.

A thorough analysis of the magnetic flux distribution inside the machining gap is the starting point for the interpretation of machining effects on the example of a design of experiment for AISI 303L steel.

The information resulting from this research may be applied in practice as a guideline to construct magnetic-abrasive machining stations with higher efficiency and effectiveness of the magnetic energy of permanent magnets. 


\section{Materials and Methods}

Magnetic reactance depends on the material and shape of the magnetic circuit and the location of the elements generating the magnetic field, i.e., the permanent magnets [18] The material used for the magnetic circuit should have high saturation induction, an example of which is AISI 60-40-18 ductile cast iron (Table 1). The actual (measured) magnetizing curve is shown in Figure 2 [19].

Table 1. Material designation, properties, and chemical composition of nodular cast iron alloy AISI 60-40-18 [20].

\begin{tabular}{cccc}
\hline \multicolumn{2}{c}{ Material Designation and Properties } & \multicolumn{2}{c}{ Chemical Composition [\%] } \\
\hline Grade AISI & $60-40-18$ & $\mathrm{C}$ & $3.5-3.8$ \\
Grade DIN & GGG-40 & $\mathrm{Mn}$ & $0.15-0.35$ \\
Grade BS & $420 / 112$ & $\mathrm{Si}$ & $2.2-2.8$ \\
Tensile strength $R_{m} \min [\mathrm{MPa}]$ & 400 & $\mathrm{P}$ & $0.02-0.06$ \\
Proof stress $R_{0.2 \text { min }}[\mathrm{MPa}]$ & 250 & $\mathrm{~S}$ & $0.01-0.025$ \\
Relative elongation $A_{5}[\%]$ & 12 & $\mathrm{Mg}$ & $0.03-0.065$ \\
\hline
\end{tabular}

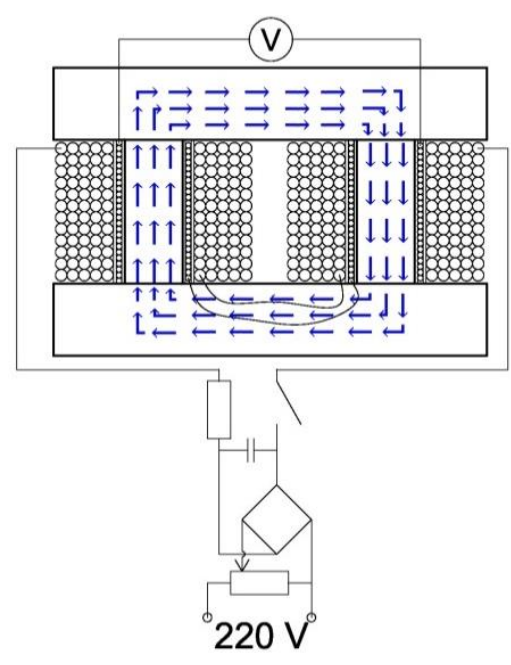

(a)

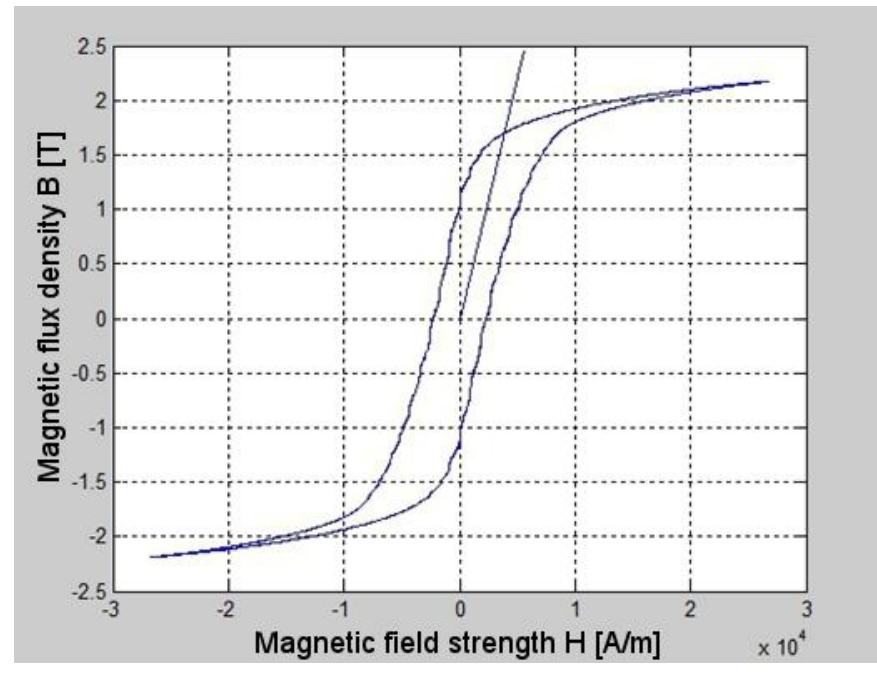

(b)

Figure 2. Magnetization characteristics of nodular cast iron alloy AISI 60-40-18: (a) measurement scheme; (b) hysteresis of casting iron magnetization.

The magnetomotive force is produced using neodymium magnets, the parameters and characteristics of which are shown in Table 2 and Figure 3.

Table 2. Characteristics of permanent magnets [21].

\begin{tabular}{cc}
\hline \multicolumn{2}{c}{ Permanent Magnet (N42). } \\
\hline Dimensions $[\mathrm{mm}]$ & $\phi 50 \times 20$ \\
Magnetic flux $\phi_{0}[\mathrm{~Wb}]$ & 0.107 \\
Coercion $j H_{c}[\mathrm{kA} / \mathrm{m}]$ & 1091 \\
Residual magnetism $B_{r}[\mathrm{~T}]$ & 1.28 \\
Energy density $\left(B H_{\max }\right)\left[\mathrm{kJ} / \mathrm{m}^{3}\right]$ & $318-342$ \\
Maximum temperature $\left[{ }^{\circ} \mathrm{C}\right]$ & 80 \\
\hline
\end{tabular}




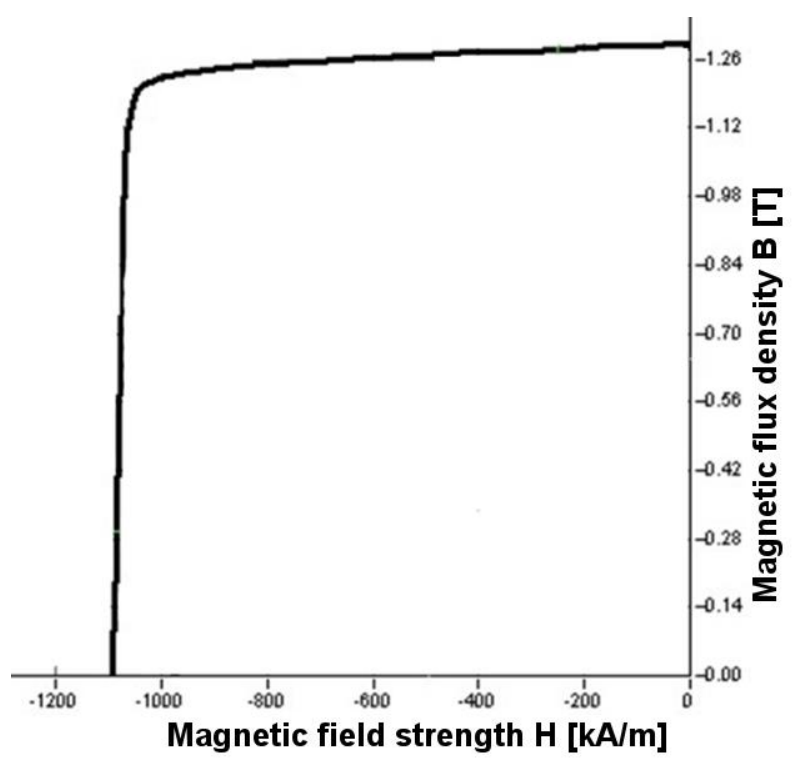

Figure 3. Magnetization characteristics of permanent magnet N42 [22].

A vector model (Figure 4), which was examined using finite element method analysis, was created for the magnetic circuit used in the experiment consisting of an AISI 60-40-18 cast iron element, permanent magnets, and an adjustable machining gap. The finishing zone was separated from the magnets by duralumin separators [23].

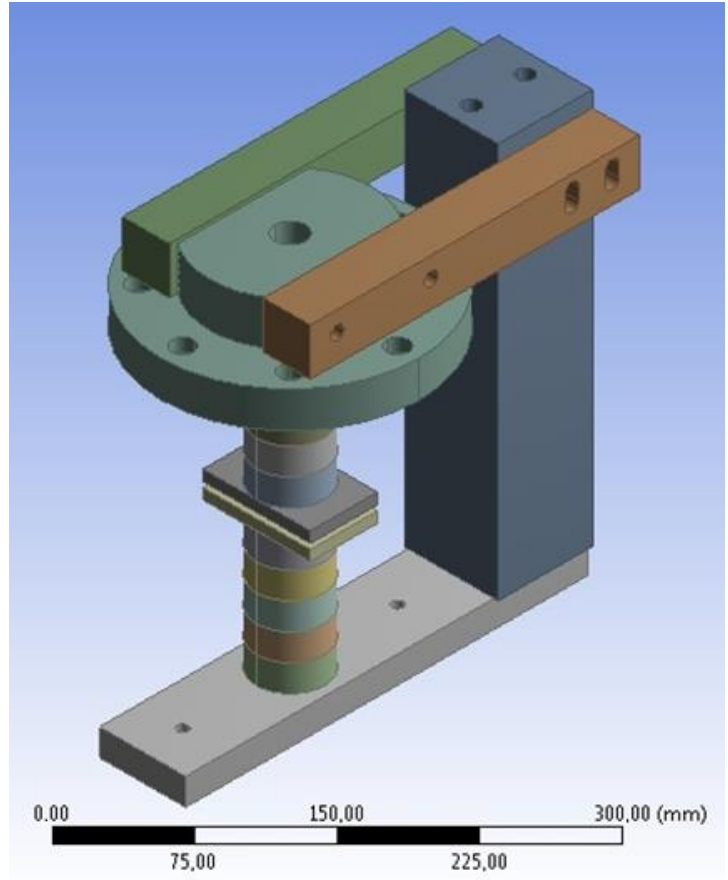

(a)

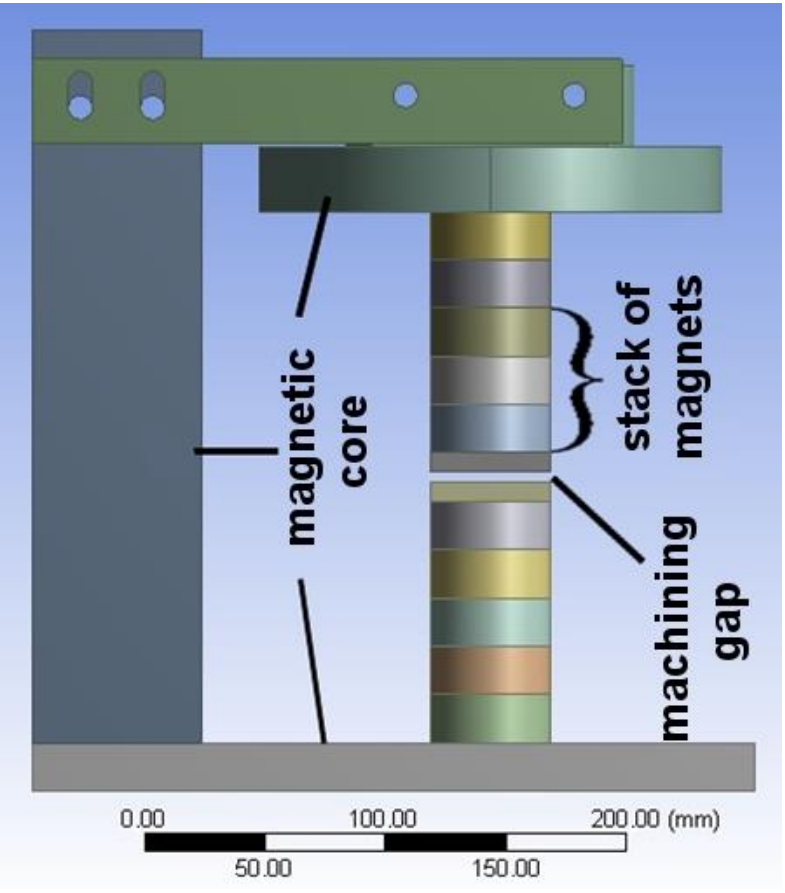

(b)

Figure 4. A magnetic model of the magnetic circuit: (a) isometric view; (b) scheme.

The model had a plane of symmetry, which was also the reference plane for magnetic induction vectors. The number of nodes in the model was approximately one million (depending on the machining gap width). 
The magnetic field distribution in the machining gap largely depends on the magnetic properties of the workpiece. In the process of modeling the magnetic flux density, the influence of the magnetic properties of the workpiece was not taken into account because the proposed construction of the magnetic circuit was dedicated to the finishing of nonferromagnetic objects. In the proposed model, due to the constructional features of the experimental station, the adopted air gap adjustment range was from 10 to $30 \mathrm{~mm}$. After taking into account the thickness of the separators ( $4 \mathrm{~mm}$ each), the actual machining gap size (distance between the upper and lower magnet stacks) was in the range from 18 to $38 \mathrm{~mm}$.

The calculations were carried out in the magnetostatic module in ANSYS 2019 R3 software (ANSYS Inc., Canonsburg, PA, USA). Parameters of the computer on which the calculations were made: AMD FX-6100 6-core 3.3 GHz, 8 GB DDR3, AMD Radeon HD 7700 (Advanced Micro Devices Inc., Sunnyvale, CA, USA).

Three simulation variants were carried out for this range. The first variant assumed placing one magnet in the upper stack and one in the lower stack (closest to the machining gap). In the second and third variants, two and three magnets, respectively, were placed in both stacks. The other elements, except for the separators, were defined as cast iron.

In order to verify the simulation results, an experimental station was built (Figure 5), the design of which made it possible to concentrate the magnetomotive energy in the machining gap. In addition, the experimental station was equipped with a mechanism for changing the size of the machining gap and adapted so that more induction coils could be added.
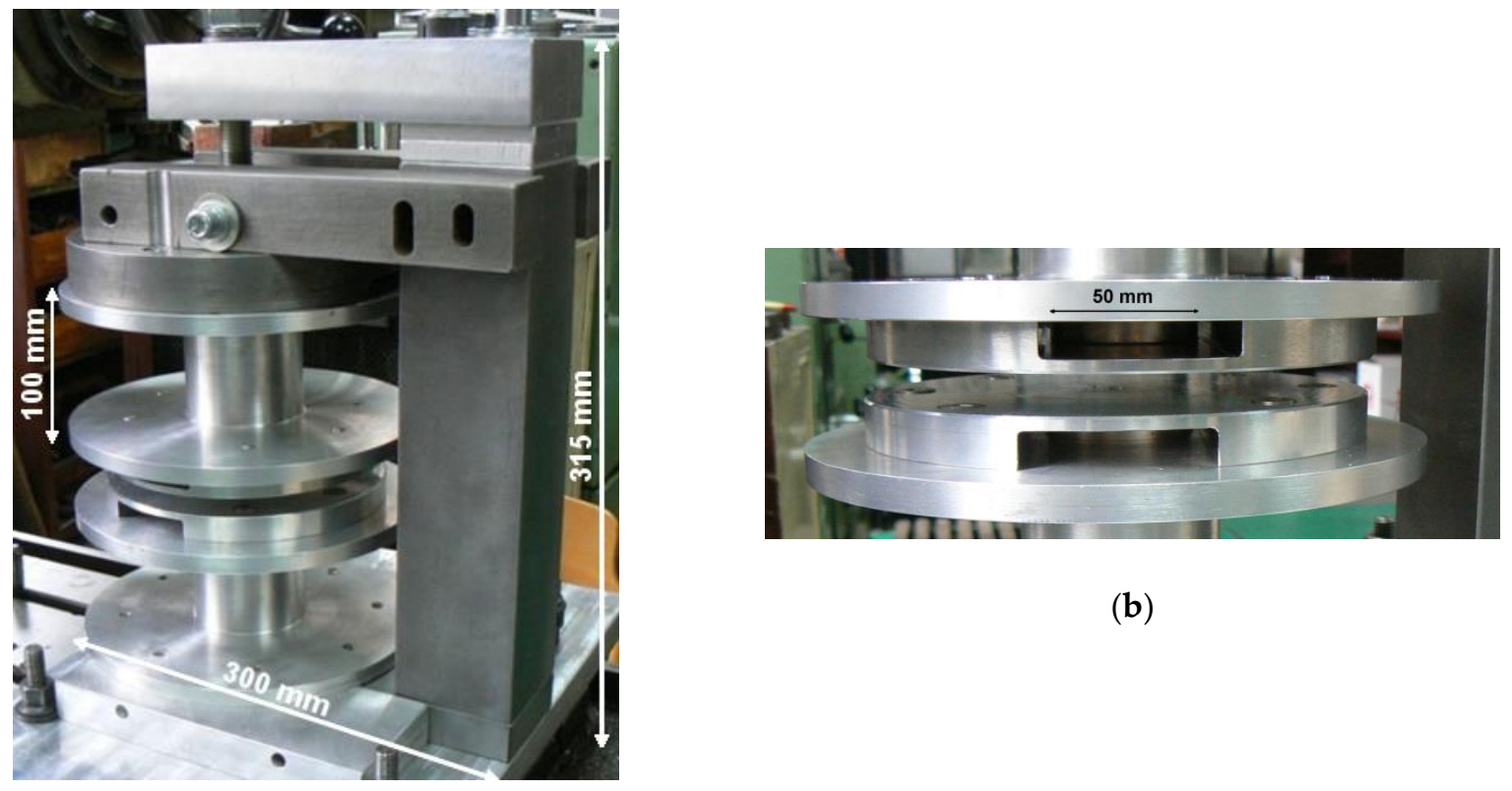

(b)

(a)

Figure 5. View of the experimental station for magnetic abrasive machining: (a) general view; (b) machining gap.

Three neodymium magnets were installed in the upper and lower heads. Measurements of the maximum magnetic flux density values were carried out at the points corresponding to the measurements from the simulation.

The real magnetic flux density values in the hollow machining gap were measured using the LZ-614H Hall Effect Sensor (ENES MAGNESY Paweł Zientek sp. k., Stare Babice, Poland). The measurement accuracy was $\pm 2 \times 10^{-3} \mathrm{~T}$, and its distribution on the $\mathrm{X}$ and $\mathrm{Y}$ axes was $2 \mathrm{~mm}$. Due to the probe's constructional limitations, the measurement on the $Z$ axis was performed at an initial distance of $6 \mathrm{~mm}$ from the surface of the magnets and then in $3 \mathrm{~mm}$ increments (Figure 6). 


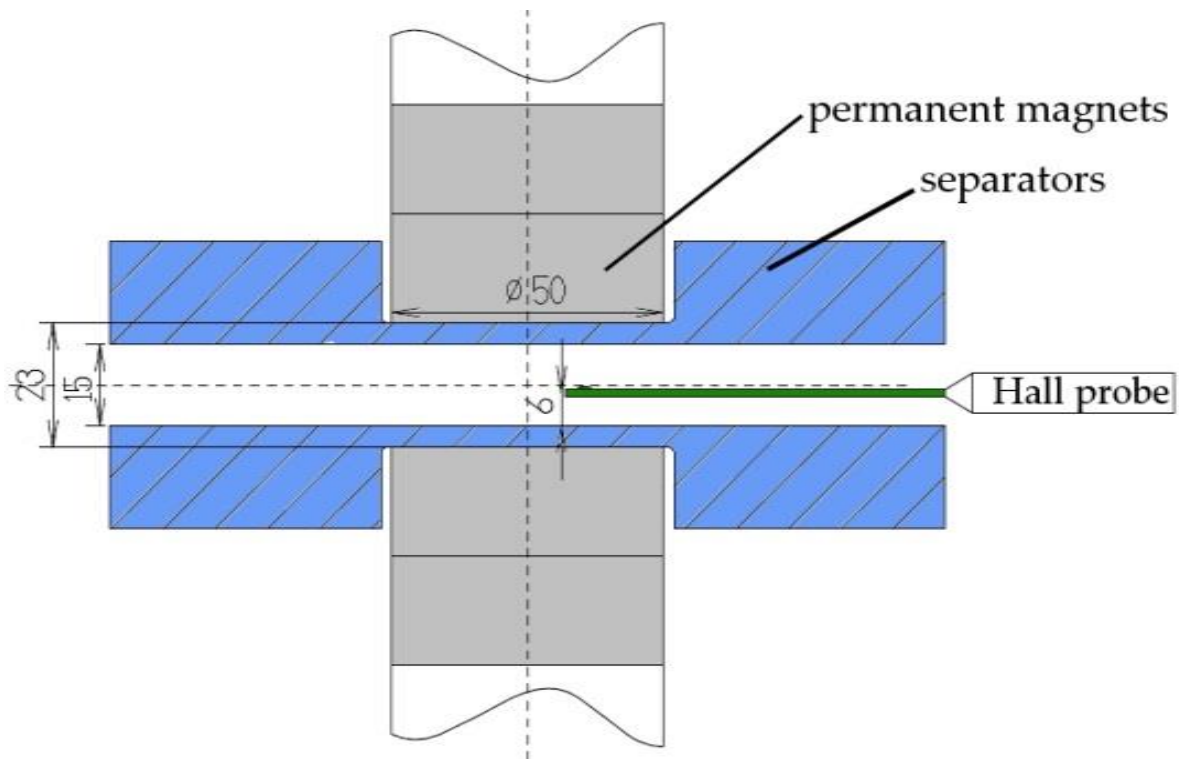

Figure 6. Scheme of measuring the real value of magnetic flux density with the LZ-614H probe in mm.

The next stage of the study was a design of experiment for the ranges of machining parameters selected on the basis of the literature [24]. We determined three parameters with the greatest expected machining results.

1. Concentration of abrasive grains $K[\%]$. This was determined on the basis of the machining gap dimensions at a limited volume of field interaction between the upper and lower magnets, and then converted to abrasive grain mass for each sample. For each gap width, the volume of the machining zone was calculated by taking a cylinder with a diameter of $50 \mathrm{~mm}$ (diameter of the magnets). For a known container volume, the mass of abrasive grains was measured to obtain the volume density. The mass of abrasive grains that should be delivered to the machining zone in each test was calculated.

2. Machining gap width $S[\mathrm{~mm}]$. This is the distance between the stacks of upper and lower magnets. It was calculated as the width of the machining gap after taking into account the separators holding the magnets and separating the abrasive grains from them.

3. Machining time $T$ [min]. This was selected on the basis of literature data.

Other parameters were set as follows:

- $\quad \operatorname{rpm} n=85 \mathrm{rpm}$ (average machining speed $V=80 \mathrm{~m} / \mathrm{min}$, for diameter from axis to center of machining area $d=300 \mathrm{~mm}$ ),

- abrasive grains Fe-TiC 315/200 ( 30 $\mu \mathrm{m})$,

- $\quad$ AISI 304L stainless steel (Table 3), dimensions of round plate equal $\phi 370 \mathrm{~mm} \times 2 \mathrm{~mm}$.

Table 3. Designation, parameters, and chemical composition of 304L stainless steel [25].

\begin{tabular}{cccc}
\hline Standard/Parameters & Mark/Value & \multicolumn{2}{c}{ Chemical Composition[\%] } \\
\hline Grade AISI & $304 \mathrm{~L}$ & $\mathrm{C}$ & 0.03 \\
Grade DIN & 1.4307 & $\mathrm{Mn}$ & 2 \\
Grade BS & $304 \mathrm{~S} 11$ & $\mathrm{Si}$ & $\leq 1$ \\
Tensile strength $R_{m} \min [\mathrm{MPa}]$ & 620 & $\mathrm{P}$ & 0.045 \\
Proof stress $R_{0.2 \min }[\mathrm{MPa}]$ & 310 & $\mathrm{~S}$ & 0.03 \\
Relative elongation $A_{5}[\%]$ & & $\mathrm{Cr}$ & $18-20$ \\
& 45 & $\mathrm{Ni}$ & 10.5 \\
& & $\mathrm{~N}$ & 0.1 \\
\hline
\end{tabular}


Courtesy of the POLIMAG company, we were able to use solid ferromagnetic abrasive grains, which are characterized by better performance than mixtures of abrasive grains [26] and magnetic particles and are better than sintered abrasive grains in the process of magnetic abrasive machining [27-29].

In order to investigate the influence of selected input parameters on surface roughness, a five-level, three-factor, rotatable, orthogonal design of Hartley's experiment was used (Figure 7), for which the value of the arm of the star radius at 20 tests was $a=1.682$ [23] (Table 4).

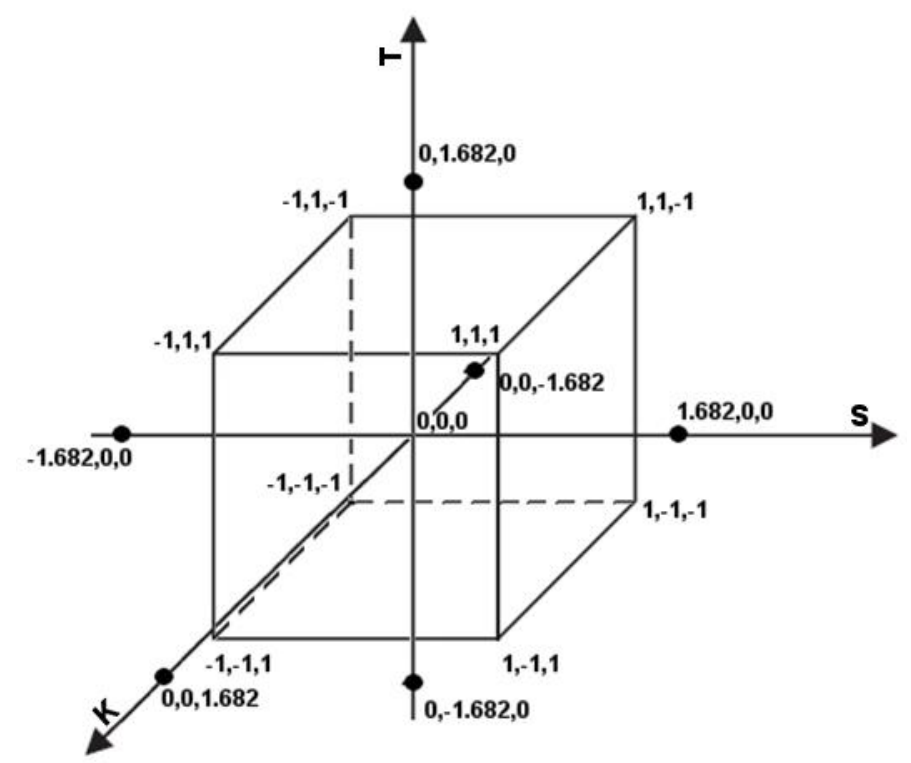

Figure 7. A graphical representation of the design of experiment in a simple 3-parameter experimental space.

Table 4. Values of input parameters of the design of experiment.

\begin{tabular}{cccccc}
\hline Star $\operatorname{arm} a$ & -1.682 & -1 & 0 & 1 & 1.682 \\
\hline$S[\mathrm{~mm}]$ & 15 & 18 & 23 & 28 & 35 \\
$T[\mathrm{~min}]$ & 7 & 10 & 15 & 20 & 27 \\
$K[\%]$ & 16 & 30 & 50 & 70 & 84 \\
\hline
\end{tabular}

The design of the experiment with real values, calculations of the abrasive grain mass $\mathrm{m}$ [g] and their concentration, and width of the machining gap between separators $\mathrm{h}$ [mm], is presented in Table 5 .

The samples were sandblasted before machining in order to homogenize the surface. After each test, we measured selected roughness parameters, flatness, weight loss, the condition of the surface obtained as a result of machining, and the shape of the abrasive tool (Figure 8). 
Table 5. Hartley's five-level, three-factor, rotatable, orthogonal design of experiment with real values.

\begin{tabular}{cccccc}
\hline Nr. & $\boldsymbol{K}[\boldsymbol{\%}]$ & $\boldsymbol{S}[\mathbf{m m}]$ & $\boldsymbol{T}[\mathbf{m i n}]$ & $\boldsymbol{m} \mathbf{[ g ]}$ & $\boldsymbol{h}[\mathbf{m m}]$ \\
\hline 9 & 50 & 15 & 15 & 4.55 & 7 \\
1 & 30 & 18 & 10 & 6.82 & 10 \\
3 & 30 & 18 & 20 & 6.82 & 10 \\
13 & 16 & 23 & 15 & 7.28 & 15 \\
5 & 70 & 18 & 10 & 15.92 & 10 \\
7 & 70 & 18 & 20 & 15.92 & 10 \\
2 & 30 & 28 & 10 & 20.47 & 20 \\
4 & 30 & 28 & 20 & 20.47 & 20 \\
11 & 50 & 23 & 7 & 22.75 & 15 \\
12 & 50 & 23 & 27 & 22.75 & 15 \\
15 & 50 & 23 & 15 & 22.75 & 15 \\
16 & 50 & 23 & 15 & 22.75 & 15 \\
17 & 50 & 23 & 15 & 22.75 & 15 \\
18 & 50 & 23 & 15 & 22.75 & 15 \\
19 & 50 & 23 & 15 & 22.75 & 15 \\
20 & 50 & 23 & 15 & 22.75 & 15 \\
14 & 84 & 23 & 15 & 38.21 & 15 \\
6 & 70 & 28 & 10 & 47.77 & 20 \\
8 & 70 & 28 & 20 & 47.77 & 20 \\
10 & 50 & 35 & 15 & 50.04 & 27 \\
\hline
\end{tabular}

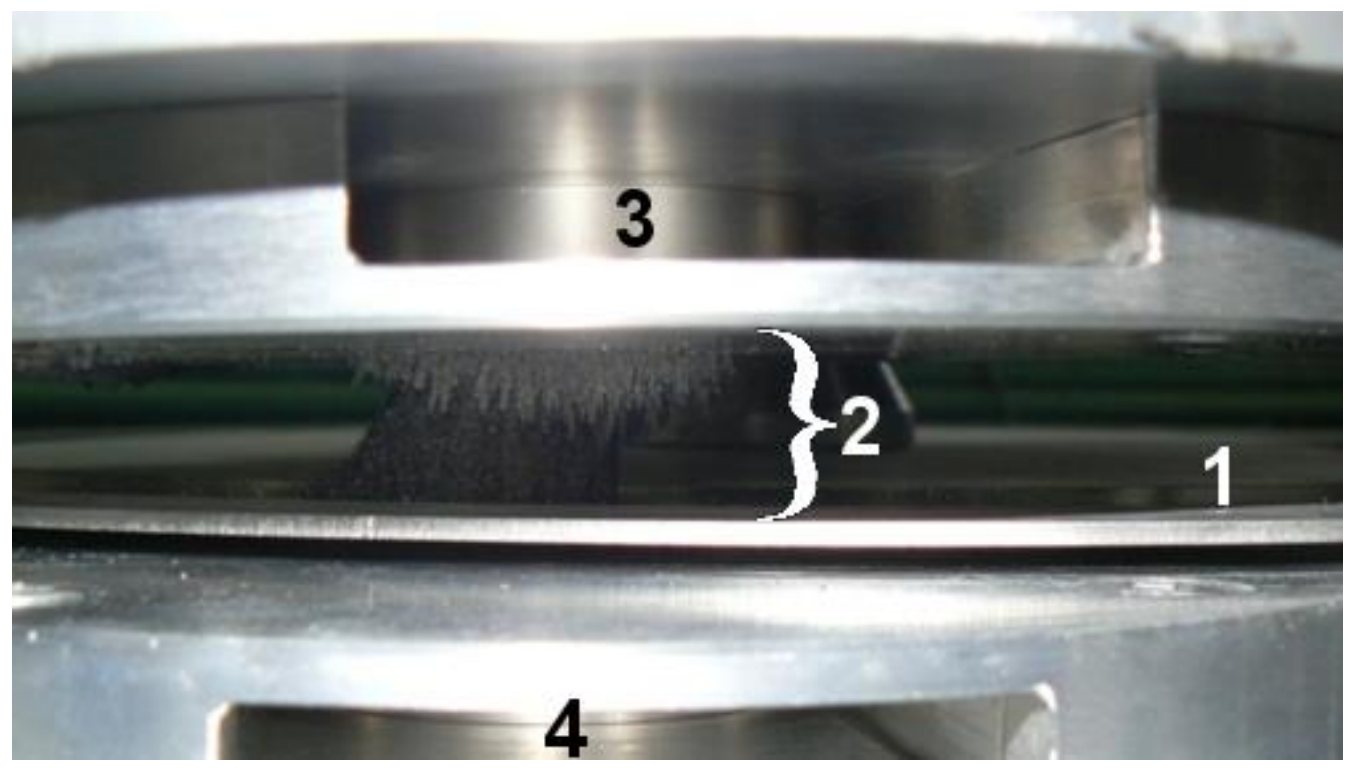

Figure 8. The shaped abrasive tool during the machining: 1—work piece, 2—flexible abrasive tool, 3,4-permanent magnets.

\section{Results and Discussion}

\subsection{Simulation}

In the machining gap, as the most interesting area, the finite element mesh was condensed in order to determine more precisely the magnetic flux density values inside it (Figure 9) [12]. A large surrounding area was adopted around the model, which made it possible to assess the magnetic fringe field closed between individual elements of the experimental station. 


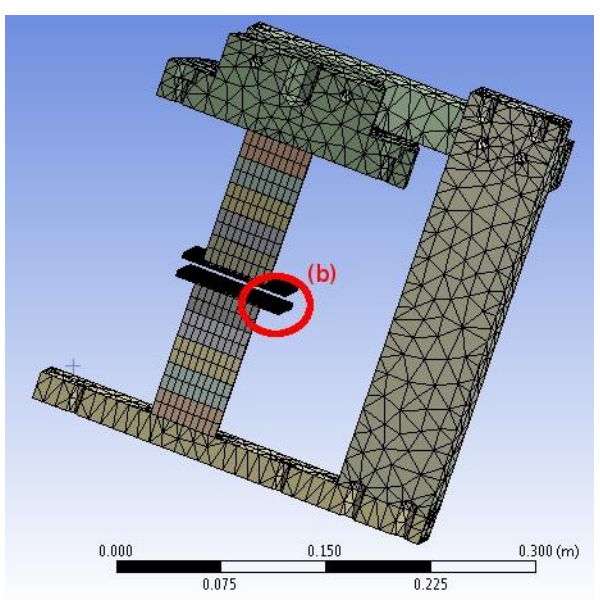

(a)

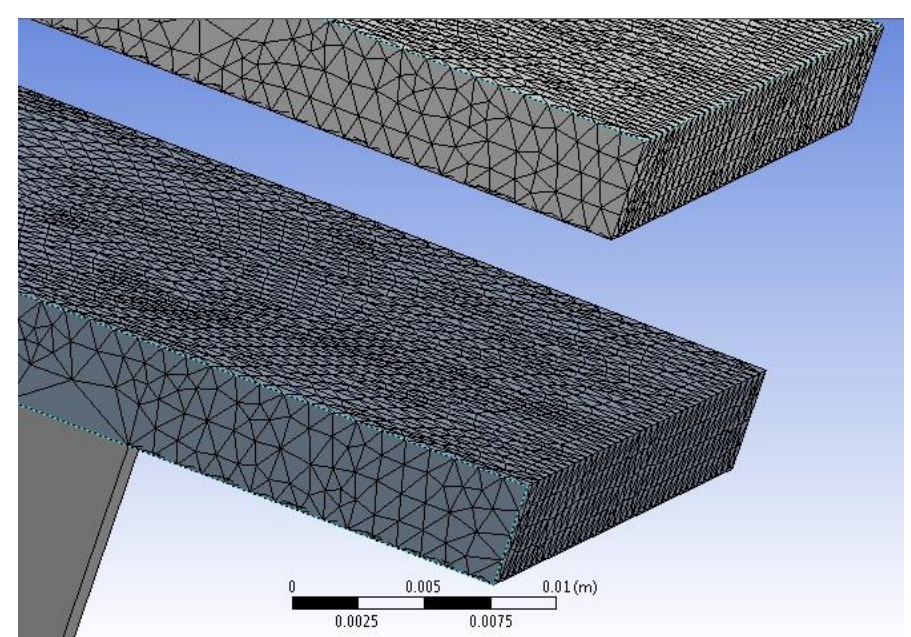

(b)

Figure 9. Mesh of finite elements (tetrahedrons, quality 0.748 , aspect ratio 2.319 , skewness 0.329 , orthogonal quality 0.675 ): (a) experimental station; (b) densification on the surface of the separators in $\mathrm{m}$.

Figure 10 shows the magnetic flux density vector image for three magnets in the stack. A significant concentration of field density can be observed in the machining gap zone and in the lower part of the base where the maximum magnetic flux density value occurs. This is the result of a high concentration of field lines in a strongly curved section of the magnetic circuit. You can also see the magnetic fringe field on the right side, closing in the area between the magnet stacks and the magnetic circuit column. The most effective-and, at the same time, difficult—solution would be a magnetic circuit in a toroidal shape that would minimize the magnetic fringe field. A summary of the simulation results is shown in Figures 11 and 12, where the central point of the machining gap and the central point on the separator surface serve as measurement points.

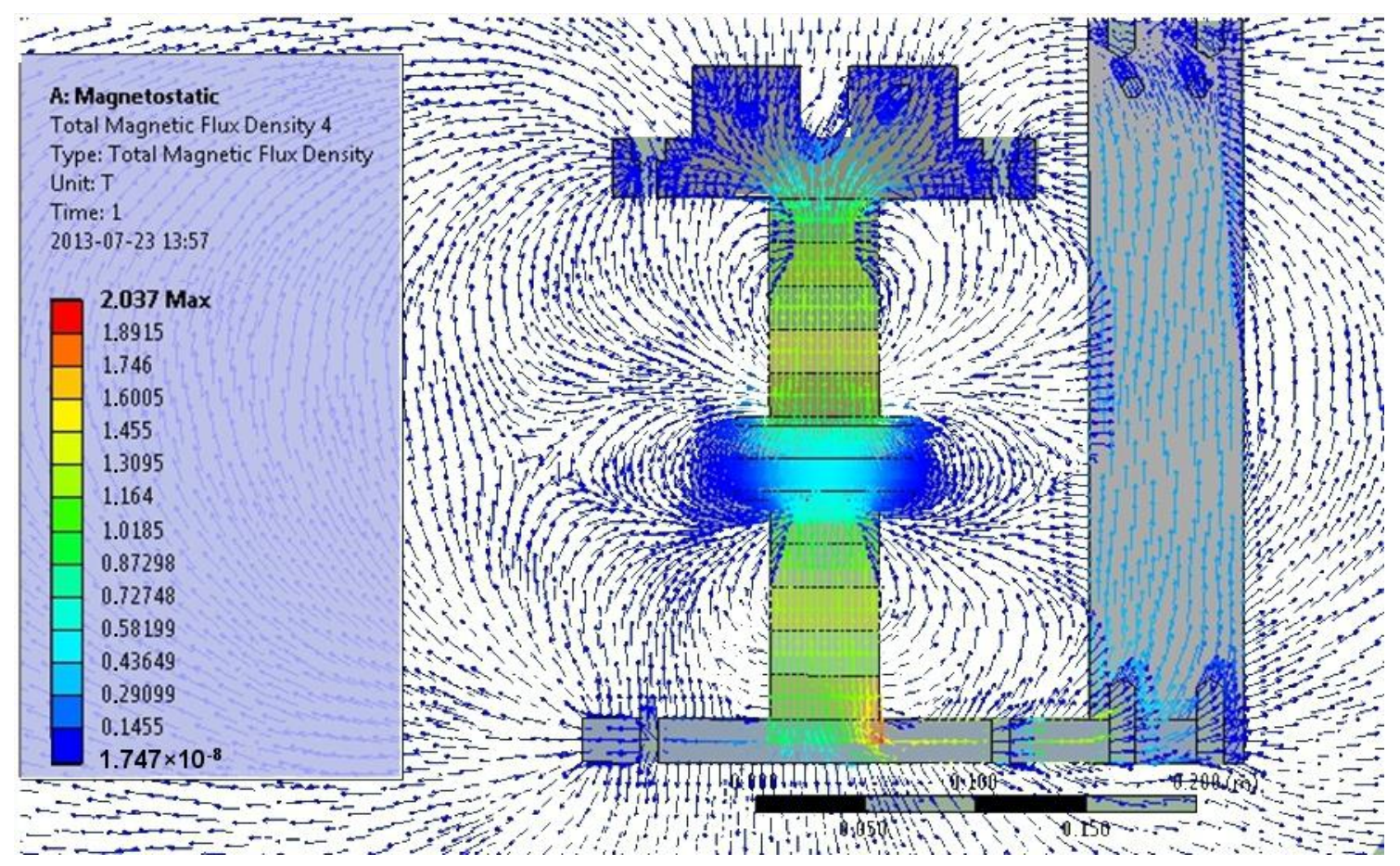

Figure 10. Vector image of the distribution of magnetic lines in a cross section. 


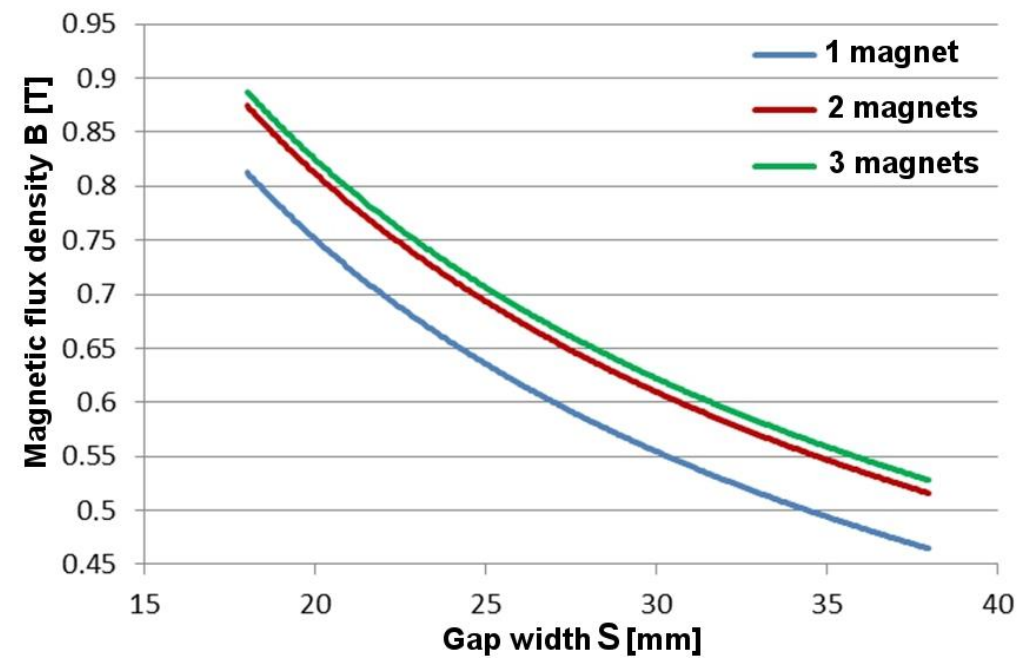

Figure 11. Impact on the magnetic flux density in the center of the machining gap area depending on the machining gap width and number of magnets, obtained from simulation.

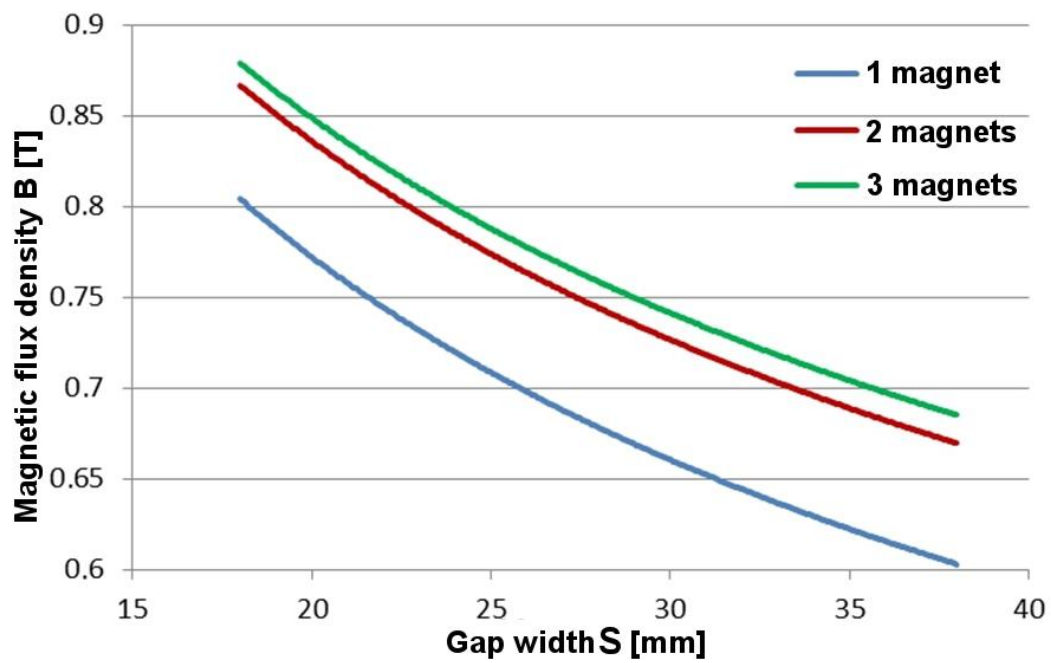

Figure 12. Impact on the magnetic flux density on the surface of separators depending on the machining gap width and number of magnets, obtained from simulation.

The nature of the curves in Figures 11 and 12 is similar. However, the distances between the curves for successive magnets in the stack are not equal. Increasing the number of magnets increases magnetic flux density only to some extent. Magnetic flux density strongly dependents on the width of the machining gap. Double increase of the width of the machining gap causes decrease of magnetic flux density in its center by about $40 \%$ and $20 \%$ on the surface of separators.

\subsection{Measurement}

In order to verify the simulation results, an experimental station was built. The measuring results of magnetic flux density are presented in Figures 13 and 14. 


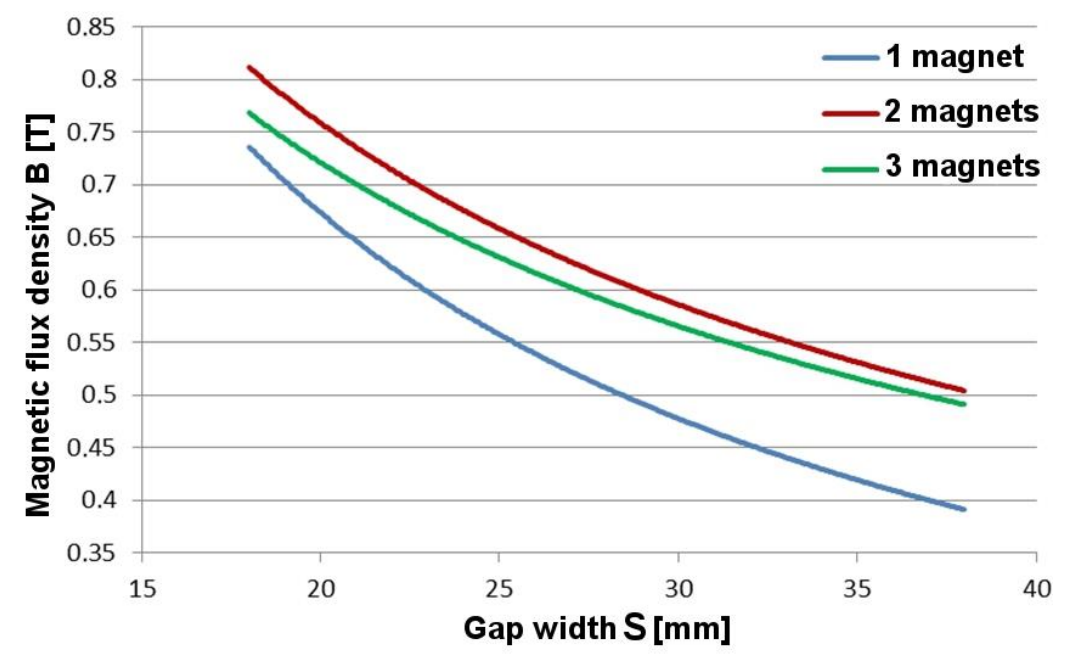

Figure 13. Impact on the magnetic flux density in the center of machining gap depending on the machining gap width and number of magnets, obtained from measurements.

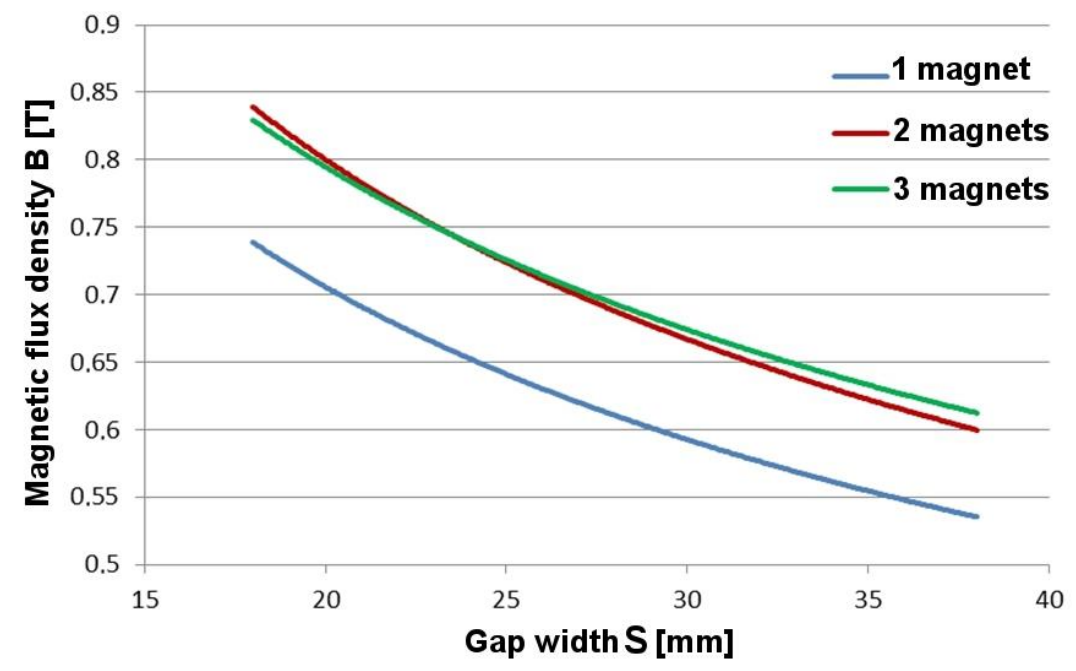

Figure 14. Impact on the magnetic flux on the surface of separators depending on the machining gap width and number of magnets, obtained from measurements.

Similarly to the simulation results, increasing the number of magnets increases the magnetic flux density only to some extent. Double increase of the machining gap results in decrease of magnetic flux density in its center by about $45 \%$ and $25 \%$ on the surface of separators.

Comparing the results of the simulation and the real measurements, one can see similar shapes of curves showing the change in the magnetic flux density as a function of the machining gap width with a varied number of magnets. The obtained simulation and measurement values are within the tolerance range of $\pm 10 \%$, which is a satisfactory result considering the difficulties resulting from modelling magnetic phenomena.

Note Figure 13, where the magnetic flux density for two magnets is higher than that for three magnets. This may be caused by a large magnetic field gradient in the machining gap, making it difficult to measure. At the same time, in Figure 11, the magnetic flux curve for two magnets is very close to the magnetic flux curve for three magnets. A very important conclusion that can be drawn from the above analysis is the fact that the increase in the magnetic flux density in the machining gap is most affected by the closest possible location of the magnets to the workpiece. Furthermore, the addition of subsequent magnets is of secondary importance, i.e., it causes only a slight increase in the magnetic flux density in 
the machining gap. In addition, increasing the number of magnets may cause concentration of the field lines in other places of the magnetic circuit and generate a significant magnetic fringe field.

The results below present measurements in the cross section through the plane of the axis of symmetry of the machining gap in the experimental station with two magnets in upper and lower stucks (Figures 15-18).

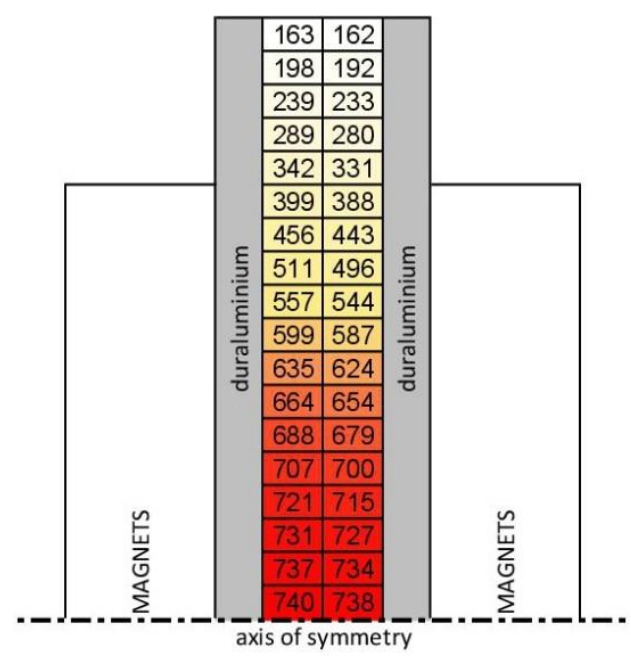

Figure 15. The results of induction distribution measurement in the machining gap $\left[\times 10^{-3} \mathrm{~T}\right]$. The distance between magnets amounts to $23 \mathrm{~mm}$.

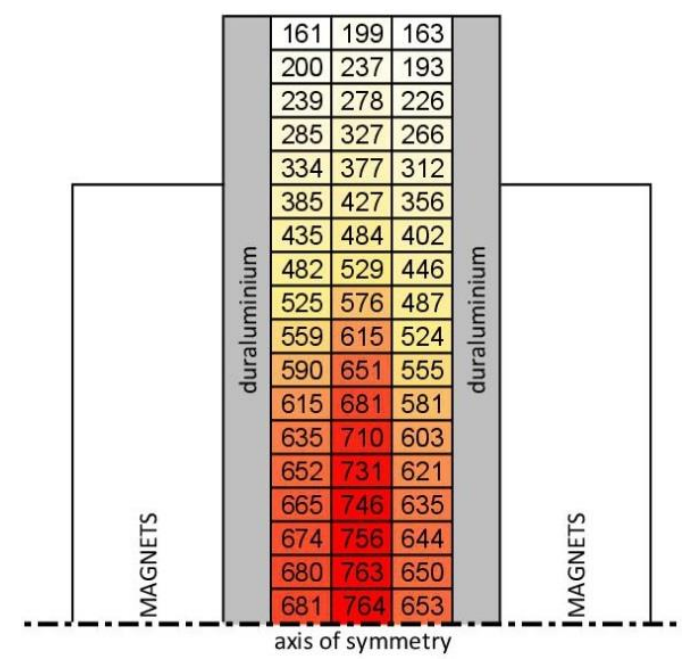

Figure 16. The results of induction distribution measurement in the machining gap $\left[\times 10^{-3} \mathrm{~T}\right]$. The distance between magnets amounts to $28 \mathrm{~mm}$. 


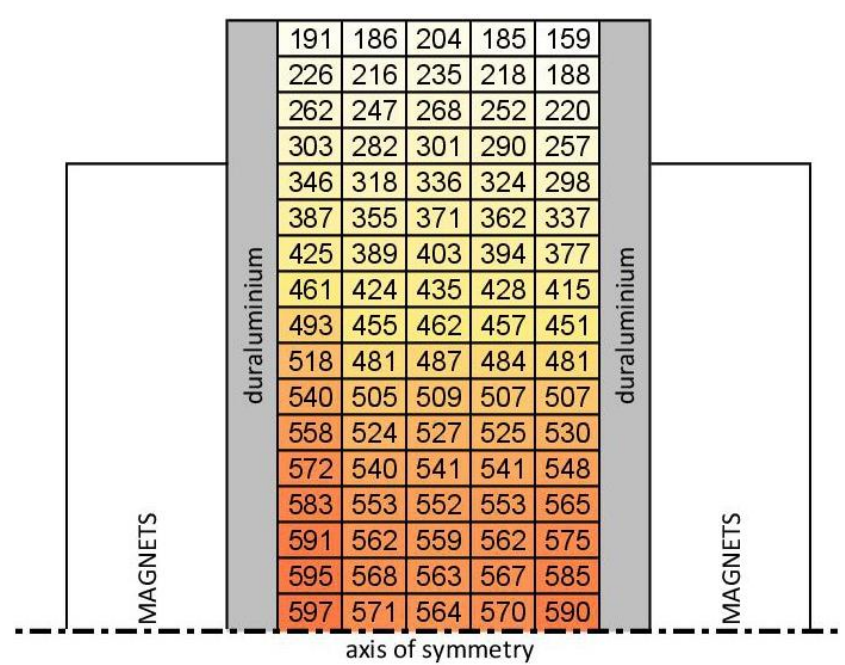

Figure 17. The results of induction distribution measurement in the machining gap $\left[\times 10^{-3} \mathrm{~T}\right]$. The distance between magnets amounts to $33 \mathrm{~mm}$.

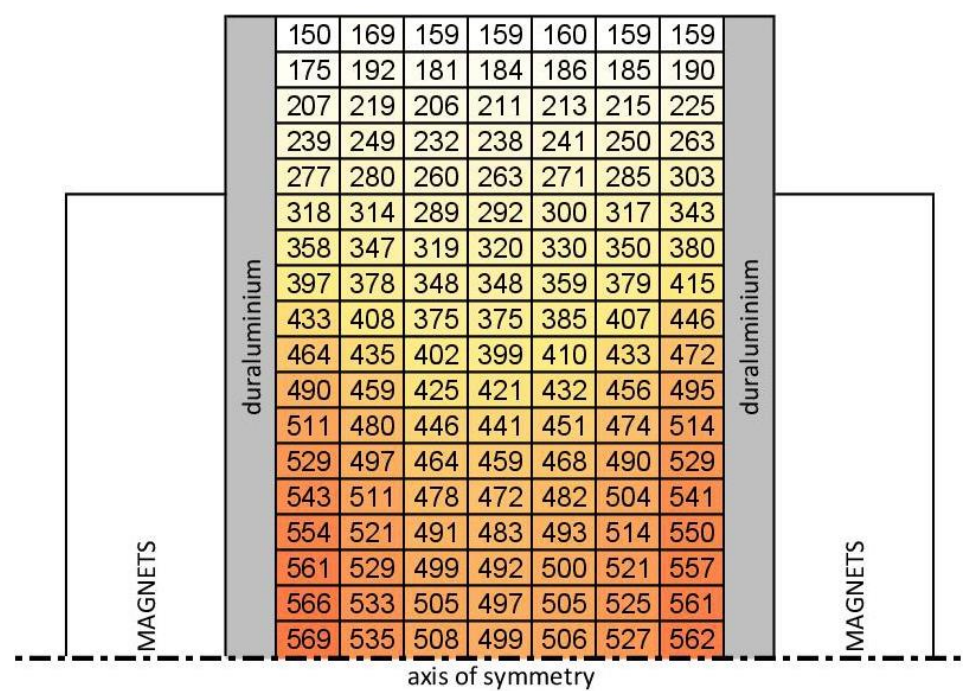

Figure 18. The results of induction distribution measurement in the machining gap $\left[\times 10^{-3} \mathrm{~T}\right]$. The distance between magnets amounts to $38 \mathrm{~mm}$.

For measurements where the distance between the magnets was $33 \mathrm{~mm}$ or more, the maximum values of magnetic flux density distribution in the machining gap were located at the surface of the magnets (Table 6). As the air gap shrunk, the maximum values were concentrated in the central part of the machining gap. If abrasive grains were introduced into the machining gap, this distribution would change.

Table 6. Maximum measured values of magnetic induction $B[\mathrm{~T}]$.

\begin{tabular}{cc}
\hline Gap $S[\mathrm{~mm}]$ & Maximal Value $\boldsymbol{B}[\mathrm{T}]$ \\
\hline 23 & 0.74 \\
28 & 0.76 \\
33 & 0.59 \\
38 & 0.57 \\
43 & 0.45 \\
\hline
\end{tabular}


The maximum magnetic flux density occurs on the separator surface. This value is all the greater if one takes into account the probe's measurement limits (minimum $6 \mathrm{~mm}$ from the surface) and the measurement error.

\subsection{Design of Experiment}

The recorded loss of the sample mass was within the limits of the measurement error $(<0.1 \mathrm{~g})$. Similar effects were obtained during measurements of sample flatness $(<3-4 \mu \mathrm{m})$ on a CNC Zeiss-Vista coordinate measuring machine (Taylor Hobson Ltd., Leicester, United Kingdom).

Moreover, the surface images under optical microscope (Figure 19) and scanning electron microscope Hitachi TM1000, TM3000, FEI Phenom (Hitachi Ltd., Tokyo, Japan) show a clear machining directionality (Figure 20) due to one working movement (rotational). On surface images you can see that roughness peaks have been removed and the surface has been smoothed. However, cavities in the material are processed to a slight extent, which may be caused by the machining speed $(80 \mathrm{~m} / \mathrm{min})$.

Before machining, the material tested was subjected to sandblasting, the purpose of which was to clean and homogenize the surface. As a result of this process, the roughness profile is irregular (anisotropic) with sharp peaks and large surface development area ratio.

By removing the sharp peaks, the surface roughness profile is similar to a plateau (Figure 20b, zoom x250), while reducing the surface development area ratio. As a result, the surface machined in this way will be less susceptible to coating. The remaining cavities visible on the surface may have a lubricating function, although due to their irregularity lubrication is less effective than in the honing process.

(a)

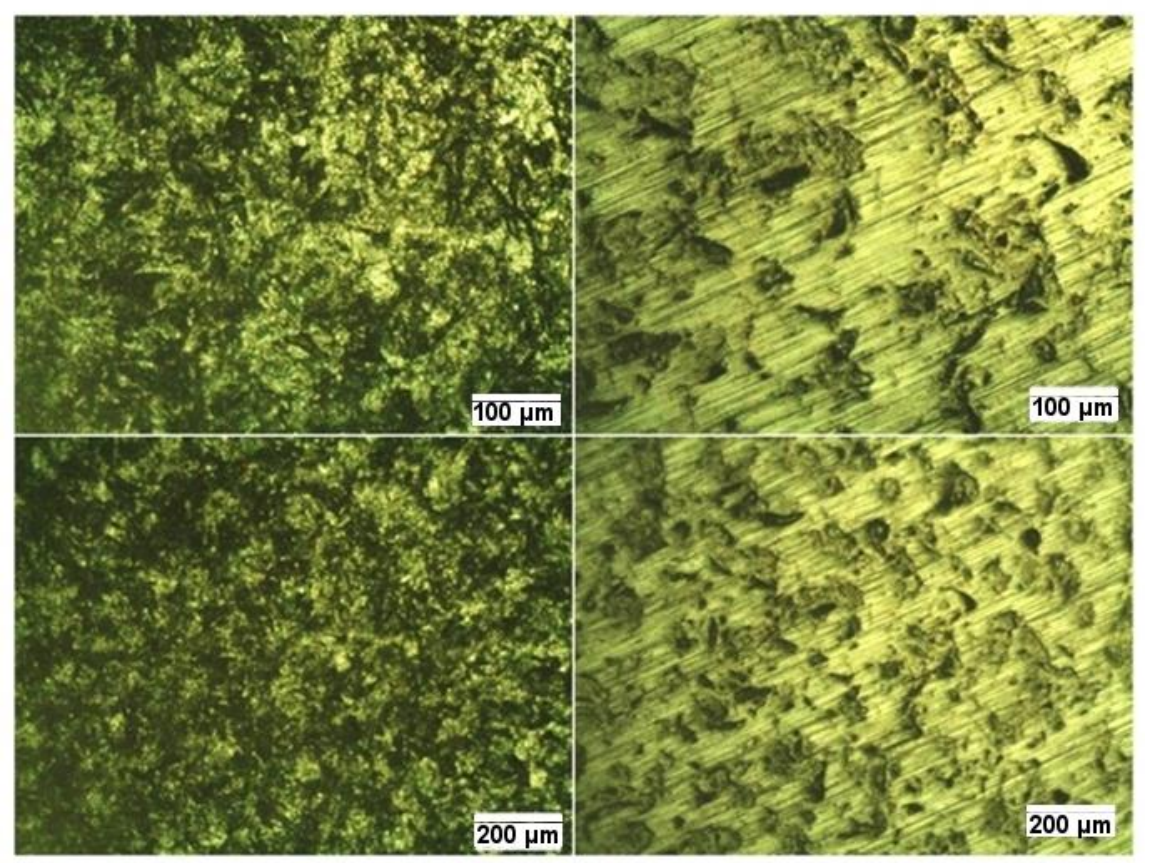

Figure 19. Surface images under optical microscope XJP-6A (Nanjing T-Bota Scietech Instruments \& Equipment Co. Ltd., Nanjing, China): (a) before machining; (b) after machining in $\mu \mathrm{m}$. 
(a)
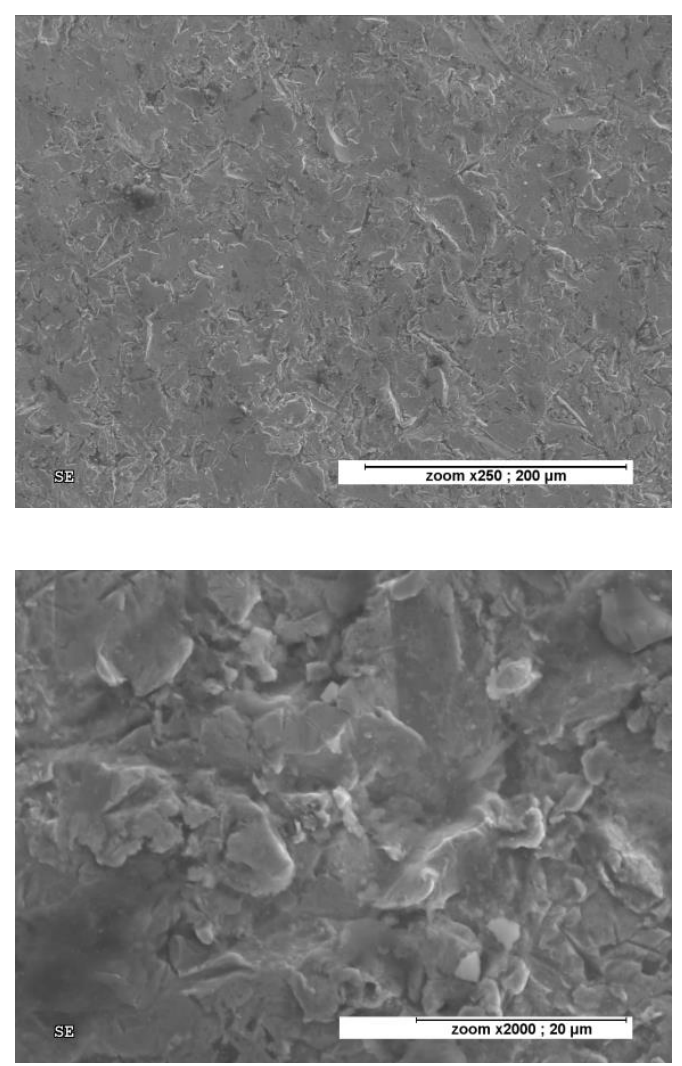

(b)
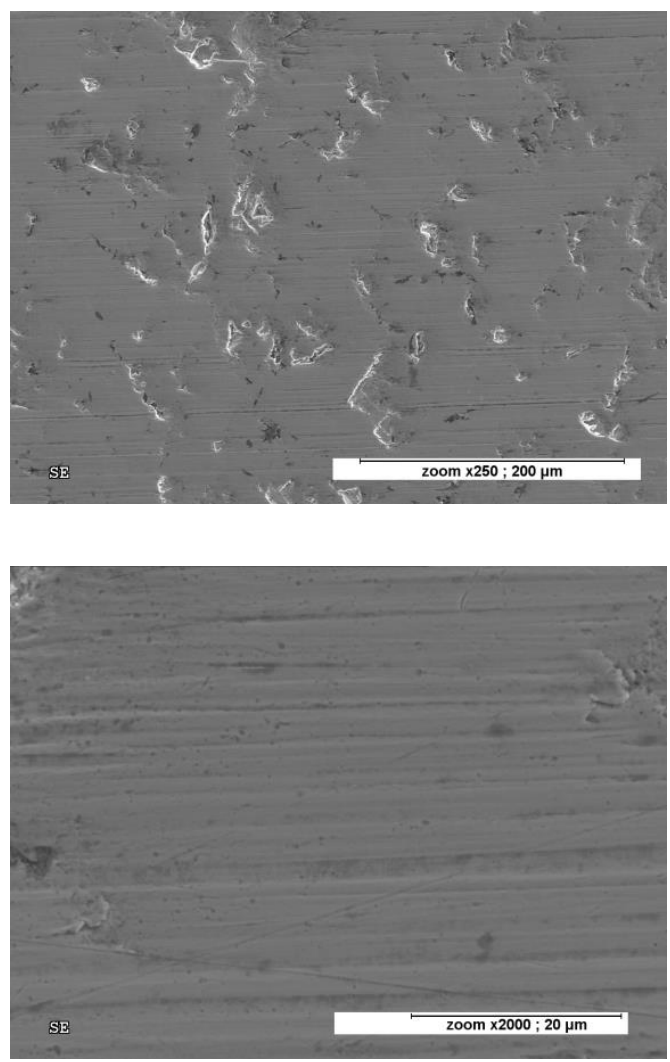

Figure 20. Surface images under SEM: (a) before machining; (b) after machining in $\mu \mathrm{m}$.

Figure 21 shows an example of a stereometric image of the surface before machining, and Figure 22 shows the same after machining. Tables 7 and 8 present the values of selected roughness parameters. The measurements were carried out on a FORM TALYSERF Series 2 scanning profilometer (Taylor Hobson Ltd., Leicester, UK).

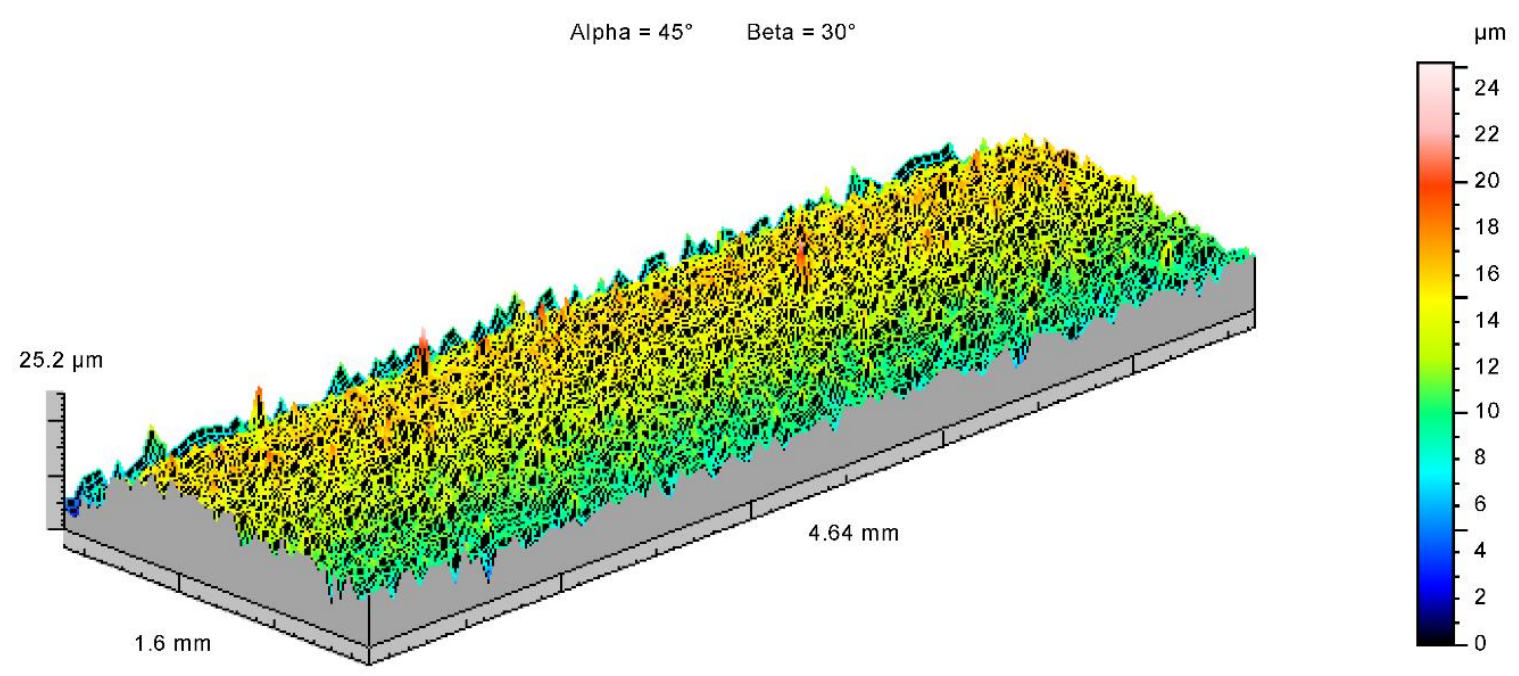

Figure 21. Stereometric surface image before machining. 


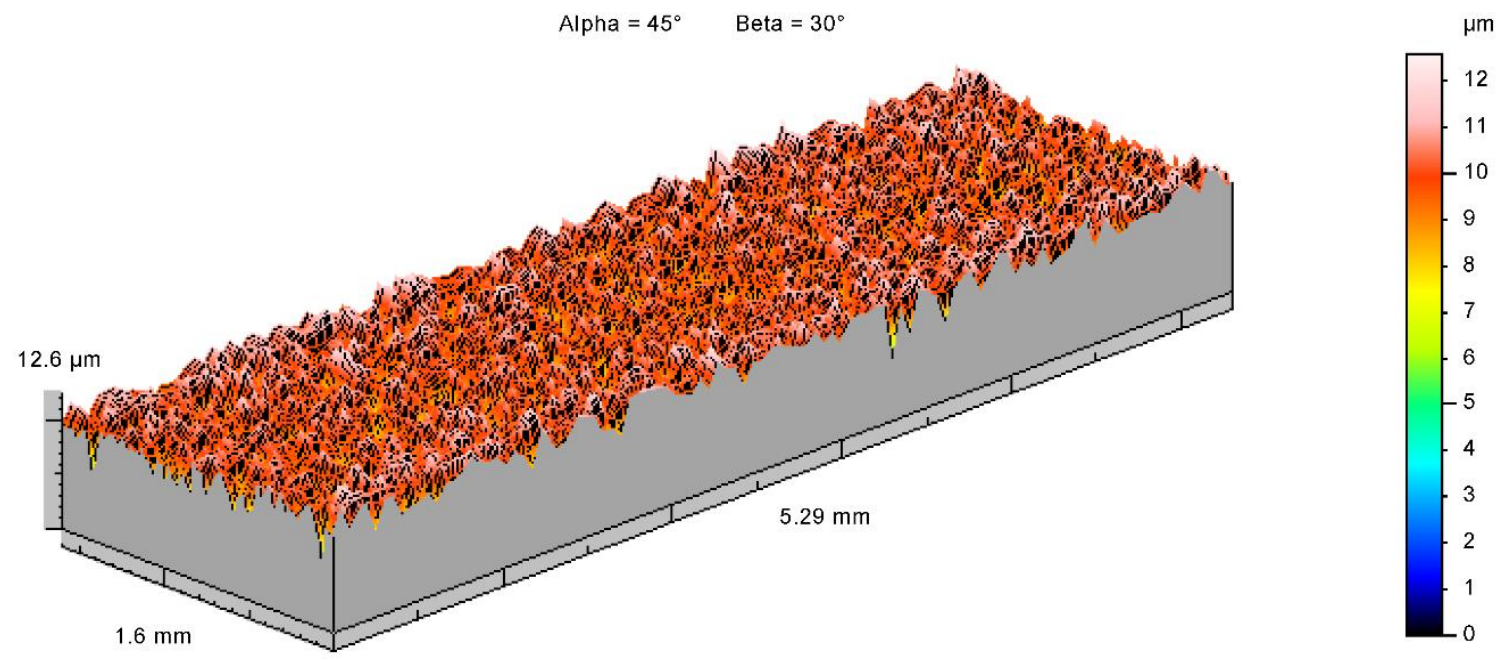

Figure 22. Stereometric surface image after machining: concentration of abrasive grains $K=50 \%$, processing time $T=7 \mathrm{~min}$, machining gap $S=23 \mathrm{~mm}$.

Table 7. Selected 3D roughness parameters.

\begin{tabular}{ccc}
\hline Roughness Parameters & Before Machining & After Machining \\
\hline$S a[\mu \mathrm{m}]$ & 2.53 & 0.85 \\
$S q[\mu \mathrm{m}]$ & 3.08 & 1.08 \\
$S t[\mu \mathrm{m}]$ & 25.2 & 12.6 \\
$S z[\mu \mathrm{m}]$ & 23.7 & 11.5 \\
\hline
\end{tabular}

Table 8. Selected 2D roughness parameters.

\begin{tabular}{ccc}
\hline Roughness Parameters & Before Machining & After Machining \\
\hline$R a[\mu \mathrm{m}]$ & 1.52 & 0.47 \\
$R q[\mu \mathrm{m}]$ & 1.73 & 0.56 \\
$R z[\mu \mathrm{m}]$ & 6.48 & 2.37 \\
$R t[\mu \mathrm{m}]$ & 9.68 & 8.68 \\
$S m[\mu \mathrm{m}]$ & 49.9 & 79.4 \\
\hline
\end{tabular}

On the basis of stereometric images of the surface, a significant reduction in amplitude from 24 to $12 \mu \mathrm{m}$ can be observed. The above images do not show any directionality of processing. The structure is disordered and random.

The obtained roughness measurement results were analyzed statistically in Statistica v.10 (TIBCO Software Inc., Palo Alto, CA, USA). We built the forward stepwise multiple regression models with statistical significance (sig. $<0.1$ ). The polynomial models were developed for selected roughness parameters; these are presented as Equations (1)-(5), where $T[\mathrm{~min}]$ is the machining time, $K[\%]$ is the concentration of abrasive grains, and $S$ [mm] is the width of the machining gap. Because the initial roughness after sandblasting was not constant for each sample ( $R a$ from 1 to $1.7 \mu \mathrm{m}$ ), the graphs show the relative change in roughness as a percentage.

$$
\begin{gathered}
\Delta \boldsymbol{R}_{a}=\left(0.39 T-0.569 S^{2}+0.685 K S\right) \times 10^{-3} \\
\Delta \boldsymbol{R}_{\boldsymbol{q}}=\left(56 T-0.774 S^{2}+0.919 K S\right) \times 10^{-3} \\
\Delta \boldsymbol{R}_{z}=\left(220 T-2.75 S^{2}-3.66 K T+3.5 K S\right) \times 10^{-3} \\
\Delta \boldsymbol{R}_{t}=\left(4510+106 T-6.38 S^{2}+6.88 K S\right) \times 10^{-3}
\end{gathered}
$$




$$
\Delta S_{m}=163-1.55 K-4.78 T-8.24 S+0.0138 K^{2}+0.151 S^{2}
$$

Residuals analysis was performed for $\Delta R a / R a$ to confirm the developed models adequacy. Analysis of the residual normal probability plots (Figure 23) indicated that the residuals had normal distributions. Plots of the residuals versus the predicted values (Figure 24) indicated that the residuals are of a stochastic nature. Analysis of the plotted residuals versus the case values showed that the error terms were independent of one another. The analysis of the residuals confirmed that the developed models were adequate.

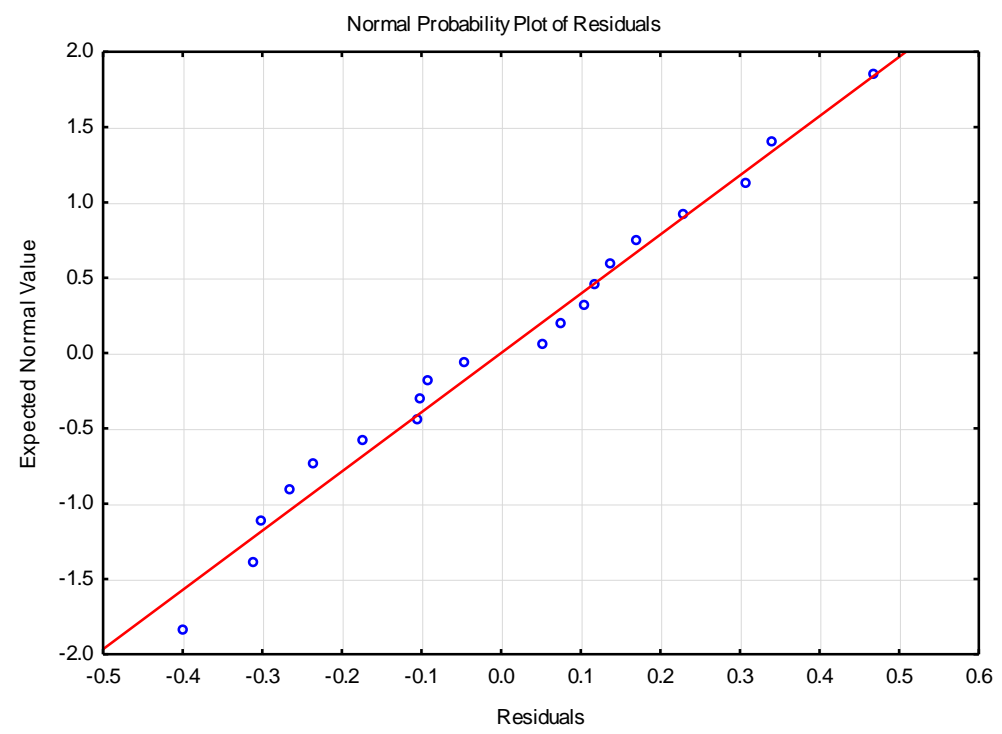

Figure 23. The normal plot of residuals for $\Delta R a / R a$.

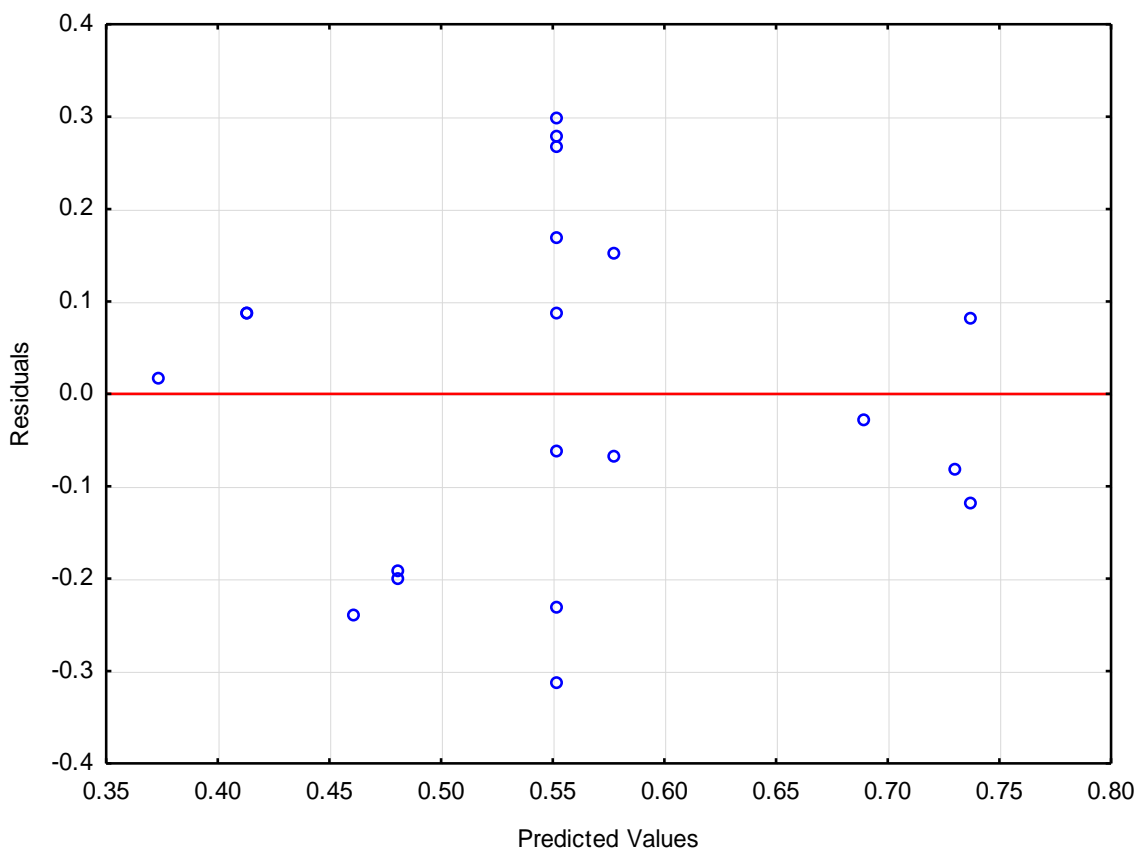

Figure 24. The residuals versus the predicted values for $\Delta R a / R a$.

The relative change of roughness parameters (Figures 25-28) for the smallest concentration of abrasive grains $(\mathrm{K}=16 \%)$ is negligible. The number of abrasive grains is not sufficient for an efficient machining process. The reason for this is the accumulation of a significant amount of abrasive grains at the top head. These grains do not take part in the machining process (Figure 30). 


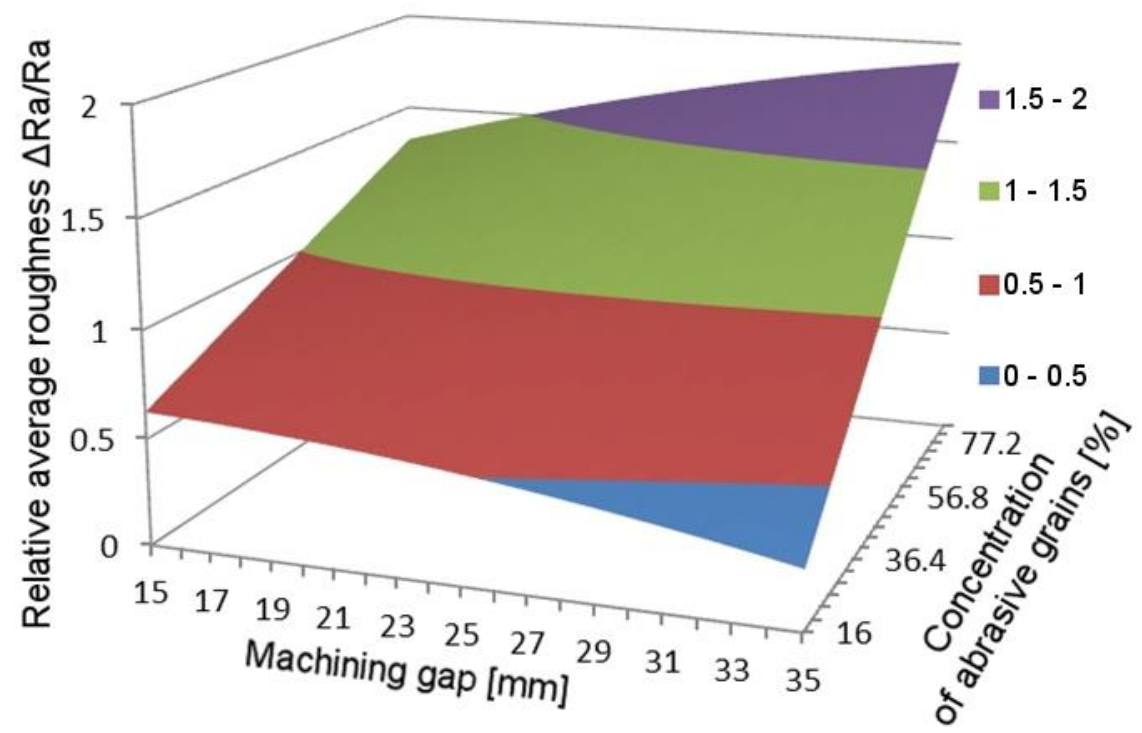

Figure 25. The impact of machining gap width and concentration of abrasive grains, at constant processing time $(T=15 \mathrm{~min}$ ), on relative change in roughness $\Delta R a / R a$ (correlation coefficient $R=0.59$ ).

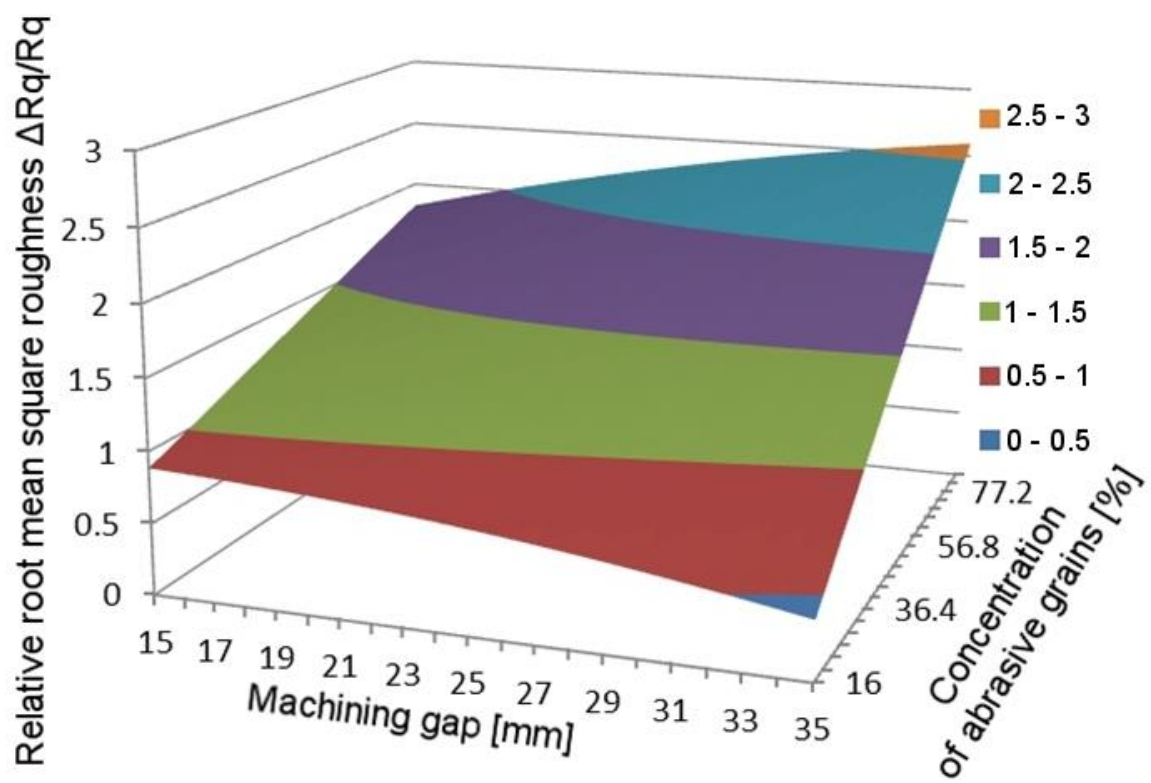

Figure 26. The impact of machining gap width and concentration of abrasive grains, at constant processing time ( $T=15 \mathrm{~min}$ ), on relative change in roughness $\Delta R q / R q$ (correlation coefficient $R=0.57)$. 


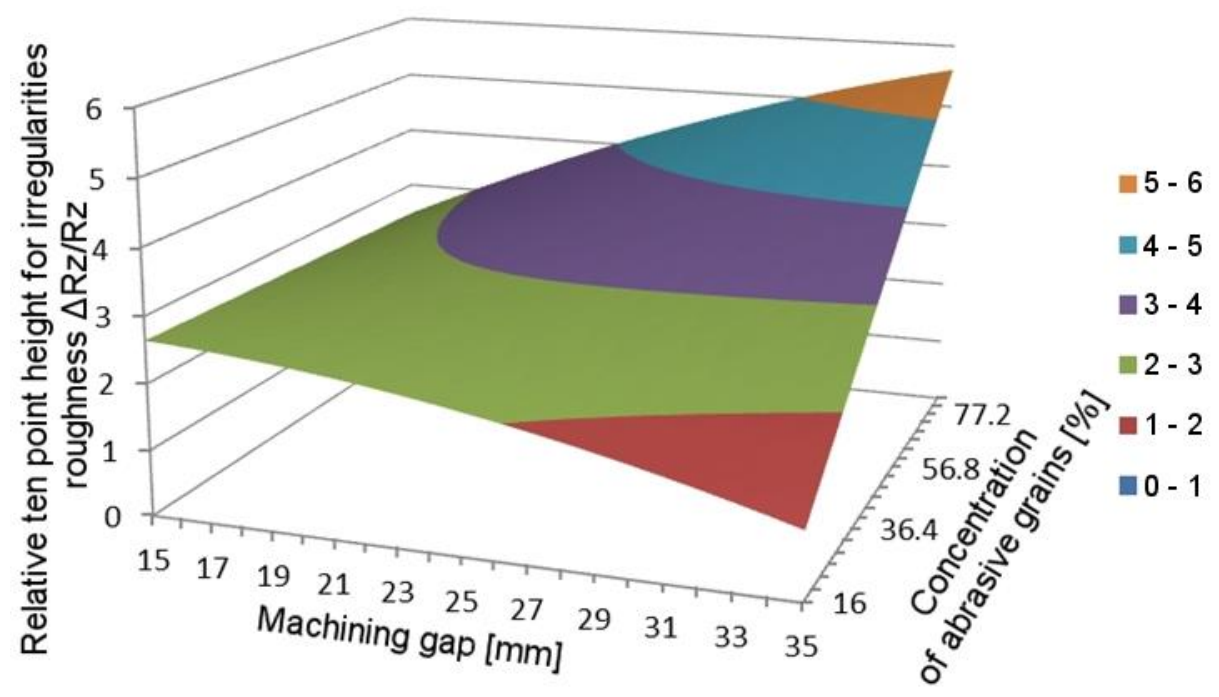

Figure 27. The impact of machining gap width and concentration of abrasive grains, at constant processing time $(T=15 \mathrm{~min})$, on relative change in roughness $\Delta R z / R z$ (correlation coefficient $=0.58$ ).

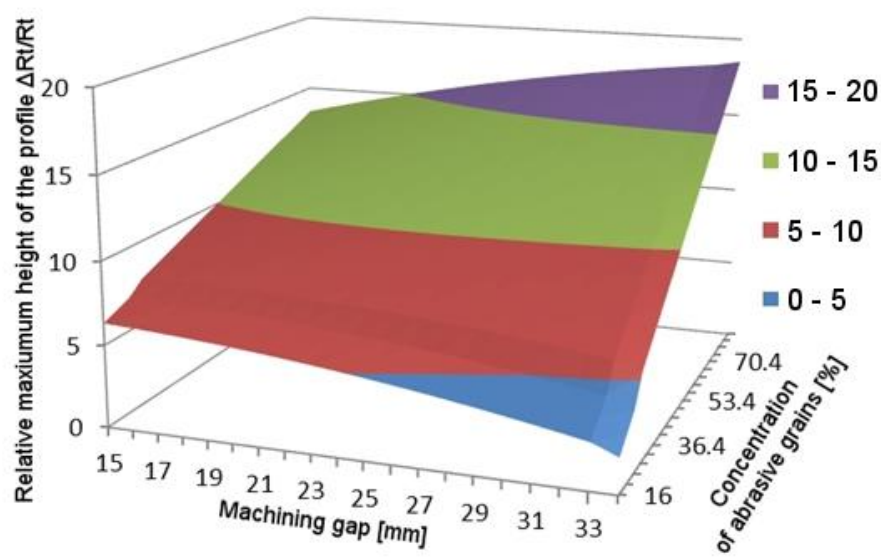

Figure 28. The impact of machining gap width and concentration of abrasive grains, at constant processing time $(T=15 \mathrm{~min})$, on relative change in roughness $\Delta R t / R t$ (correlation coefficient $R=0.57$ ).

With a concentration of more than $70 \%$, the frictional force between the workpiece and the grains may increase significantly as a result of abrasive grain jamming, which may clamp the workpiece.

The effect of the machining gap width is increasingly significant if the concentration of abrasive grains increases. With large machining gap, magnetic flux separation may occur (Figures 16-18). However, this effect should be compensated for by a high concentration of abrasive grains, which can result in a concentration of grains in the central part of the machining area, where roughness was measured.

Figures 25-27 show a change in roughness in the range from 2 to $5.6 \%$, while Figure 28 shows a change in the Rt roughness height by $18.2 \%$. This parameter is the most sensitive indicator of high peaks and deep scratches. It is highly probable that the machining removed most strongly the peaks of the roughness profile.

Figure 29 shows an improvement in the mean spacing of roughness profile irregularities by $63 \%$ for the machining gap $S=27 \mathrm{~mm}$ and abrasive grain concentration $K=56 \%$. 


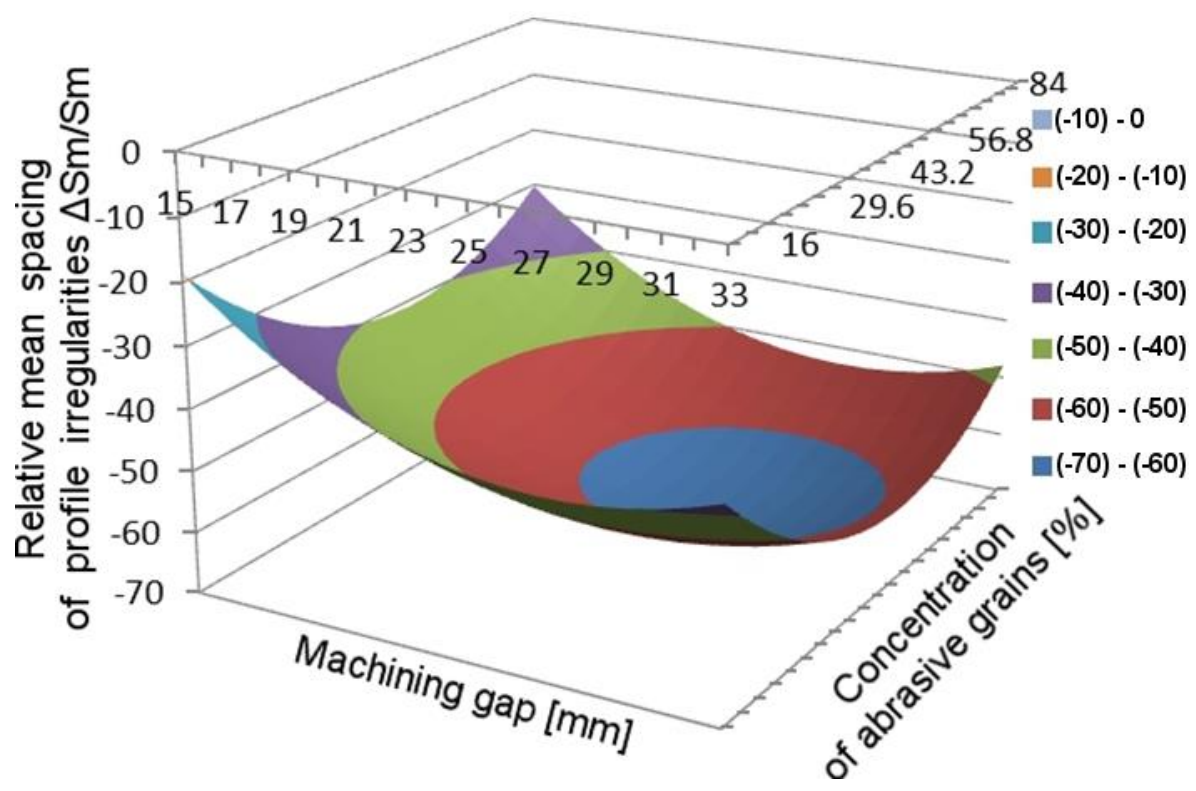

Figure 29. The impact of machining gap width and concentration of abrasive grains, at constant processing time $(T=15 \mathrm{~min}$ ), on relative change in roughness $\Delta S m / S m$ (correlation coefficient $R=0.74)$.

A correlation coefficient of $R=0.57-0.59$ indicates a moderate positive relationship for regression equations.

Abrasive grains migrate during the process. The average processing speed has been selected to prevent the grains from being thrown out of the processing zone, which would reduce the concentration of abrasive grains. However, the migration effect continues to occur. It dependents on the width of the machining gap. The larger the gap, the more grains migrate in accordance with the direction of the workpiece speed vector (Figure 30) and are then attracted by the magnetic field. This is another effect of the magnetic flux separation at large machining gap widths. It is difficult to say whether this effect is beneficial for the smoothing process. It seems to be dangerous for the life of abrasive grains.

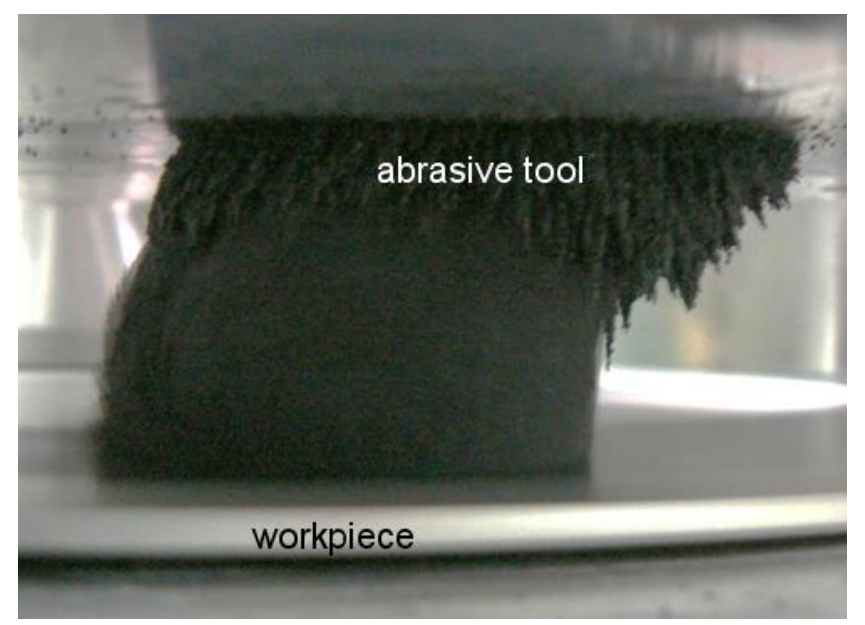

Figure 30. Migration of abrasive grains outside the machining zone during processing.

\section{Conclusions}

In this study, a numerical model of a magnetic abrasive finishing station was proposed and analyzed using the finite element method (FEM). The obtained results were compared with the real values measured on an experimental station of our own design. A design 
of experiment was carried out with the following variables: abrasive grain concentration, width of the machining gap, and process duration. The conclusions are as follows:

1. Within the assumed range of machining parameters, the surface layer of AISI 304L stainless steel improved, so that precision increased and better surface quality of manufacturing elements was achieved.

2. Based on the conducted numerical simulation we were able to determine the approximate relation between the number of magnets in the stack and the maximum magnetic flux density in the machining gap. The greater the number of magnets, the greater the value of magnetic flux density was, although this relation was not linear, which is shown by the distance between consecutive curves (Figures 7 and 8).

3. It should be noted that the difference in the values of magnetic flux density in the center of the machining gap and on the separator's surface was not constant. It grew with the number of magnets and the width of the machining gap.

4. The proposed magnetic abrasive machining station is characterized by the ability to produce significant magnetic flux density values in the range of $0.4-0.85 \mathrm{~T}$, i.e., in the upper limits of the magnetic flux density values found in the literature [30]. Such high magnetic flux density values translate into a relatively high force acting on the abrasive grain. This may partially increase the material removal rate.

5. The maximum relative change in $\Delta R a / R a, \Delta R q / R q, \Delta R z / R z$, and $\Delta R t / R t$ roughness is directly proportional to the number of abrasive grains in the working gap (Figure 22). At the same time, this does not mean that the greater the quantity of abrasive material, the greater the number of grains involved in the microcutting process.

6. The relative change of roughness parameters for the smallest concentration of abrasive grains $(\mathrm{K}=16 \%)$ is negligible. The number of abrasive grains is not sufficient for an efficient machining process. The reason for this is the accumulation of a significant amount of abrasive grains at the top head. These grains do not take part in the machining process. With a concentration of more than $70 \%$, the frictional force between the workpiece and the grains may increase significantly as a result of abrasive grain jamming, which may clamp the workpiece.

7. The effect of the machining gap width is increasingly significant if the concentration of abrasive grains increases.

8. For small machining gap widths, an increase in the concentration of abrasive grains has little effect on lowering the $R a, R q, R z$, and $R t$ roughness parameters. However, when we widen the machining gap, the concentration's impact on these parameters increases. This may result from the perpendicular movement of abrasive grains relative to the width of the machining gap (Figure 30).

9. The experiment results indicate the smooth character of the processing [31]. A very significant improvement in the roughness value was observed for certain ranges of parameters. The greatest influence can be observed for the mean spacing of profile irregularities $\mathrm{Sm}$. This is a premise to undertake further experiments that would take into account a larger number of horizontal roughness parameters (e.g., mean summit curvature, RMS surface slope).

Author Contributions: Conceptualization, M.M.; methodology, M.M.; software, J.Z.; validation, M.M. and J.Z.; formal analysis, M.M.; investigation, M.M. and J.Z.; resources, M.M.; data curation, J.Z.; writing—original draft preparation, M.M.; writing—review and editing, M.M.; visualization, J.Z.; supervision, M.M.; project administration, J.Z.; funding acquisition, M.M. paper. All authors have read and agreed to the published version of the manuscript.

Funding: This research work was supported by grant number 504/04502/1104 from the Fundamental Research Funds of the discipline of mechanical engineering, Warsaw University of Technology.

Institutional Review Board Statement: Not applicable.

Informed Consent Statement: Not applicable.

Data Availability Statement: Not applicable. 
Conflicts of Interest: The authors declare no conflict of interest.

\section{Nomenclature}

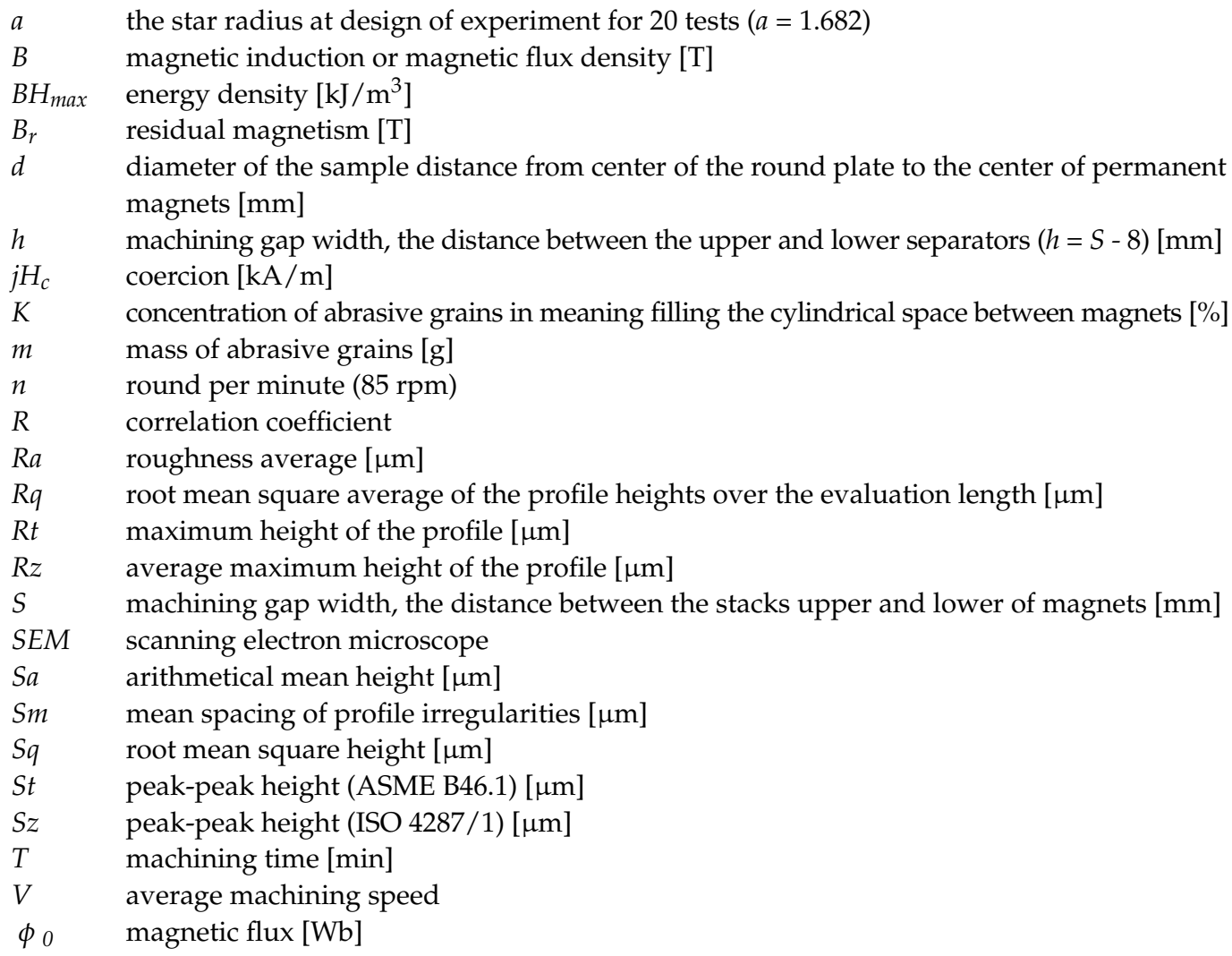

\section{References}

1. Fernandez-Zelaia, P.; Melkote, S.N. Process-structure-property relationships in bimodal machined microstructures using robust structure descriptors. J. Mater. Process. Technol. 2019, 273, 116251. [CrossRef]

2. Singh, R.K.; Gangwar, S.; Singh, D.K. Experimental investigation on temperature-affected magnetic abrasive finishing of Aluminum 6060. Mater. Manuf. Process. 2019, 34, 1274-1285. [CrossRef]

3. Kumar, S.; Singh, A.K. Magnetorheological nanofinishing of BK7 glass for lens manufacturing. Mater. Manuf. Process. 2018, 33, 1188-1196. [CrossRef]

4. Barman, A.; Das, M. Simulation and experimental investigation of finishing forces in magnetic field assisted finishing process. Mater. Manuf. Process. 2018, 33, 1223-1232. [CrossRef]

5. Kim, J.S.; Nam, S.S.; Heng, L.; Kim, B.S.; Mun, S.D. Effect of environmentally friendly oil on Ni-Ti stent wire using ultraprecision magnetic abrasive finishing. Metals 2020, 10, 1309. [CrossRef]

6. Zhang, J.; Hu, J.; Wang, H.; Kumar, A.S.; Chaudhari, A. A novel magnetically driven polishing technique for internal surface finishing. Precis. Eng. 2018, 54, 222-232. [CrossRef]

7. Singh, M.; Singh, A.K. Magnetorheological finishing of micro-punches for enhanced performance of micro-extrusion process. Mater. Manuf. Process. 2019, 34, 1646-1657. [CrossRef]

8. Singh, M.; Singh, A.K. Improved magnetorheological finishing process with rectangular core tip for external cylindrical surfaces. Mater. Manuf. Process. 2019, 34, 1049-1061. [CrossRef]

9. Grover, V.; Singh, A.K. Improved magnetorheological honing process for nanofinishing of variable cylindrical internal surfaces. Mater. Manuf. Process. 2018, 33, 1177-1187. [CrossRef]

10. Kariganaur, K.A.; Kumar, H.; Arun, M. Effect of magnetic permeability, shearing length, and shear gap on magnetic flux density of the magnetorheological damper through finite element analysis. Mater. Today Proc. 2020, S2214785320343261. [CrossRef]

11. Mosavat, M.; Rahimi, A. Numerical-Experimental study on polishing of silicon wafer using magnetic abrasive finishing process. Wear 2019, 424-425, 143-150. [CrossRef]

12. Kum, C.W.; Sato, T.; Guo, J.; Liu, K.; Butler, D. A novel media properties-based material removal rate model for magnetic field-assisted finishing. Int. J. Mech. Sci. 2018, 141, 189-197. [CrossRef]

13. Gao, Y.; Zhao, Y.; Zhang, G.; Yin, F.; Zhang, H. Modeling of material removal in magnetic abrasive finishing process with spherical magnetic abrasive powder. Int. J. Mech. Sci. 2020, 177, 105601. [CrossRef] 
14. Song, J.; Shinmura, T.; Mun, S.D.; Sun, M. Micro-Machining characteristics in high-speed magnetic abrasive finishing for fine ceramic bar. Metals 2020, 10, 464. [CrossRef]

15. Iqbal, F.; Jha, S. Experimental investigations into transient roughness reduction in ball-end magneto-rheological finishing process. Mater. Manuf. Process. 2019, 34, 224-231. [CrossRef]

16. Wu, P.-Y.; Yamaguchi, H. Material removal mechanism of additively manufactured components finished using magnetic abrasive finishing. Procedia Manuf. 2018, 26, 394-402. [CrossRef]

17. Kumar, H.; Singh, S.; Srivastava, A. Parametric investigations into internal surface modification of brass tubes with alternating magnetic field. Procedia Manuf. 2016, 5, 1234-1248. [CrossRef]

18. Singh, R.K.; Singh, D.K.; Gangwar, S. Advances in magnetic abrasive finishing for futuristic requirements-A review. Mater. Today Proc. 2018, 5, 20455-20463. [CrossRef]

19. Tumański, S. Handbook of Magnetic Measurements; Series in Sensors; Taylor \& Fracis: Boca Raton, FL, USA, 2011; ISBN 978-1-43982951-6.

20. Angus, H.T. Cast Iron; Elsevier Science: Burlington, ON, Canada, 1976; ISBN 978-1-4831-0195-8.

21. Manyala, R. A Guide to Small-Scale Energy Harvesting Techniques; IntechOpen: London, UK, 2020; ISBN 978-1-78923-910-2.

22. Permanent Magnets. 2015. Available online: www.magnesy.pl (accessed on 5 September 2018).

23. Antony, J. Design of Experiments for Engineers and Scientists, 2nd ed.; Elsevier insights; Elsevier: London, UK, 2014; ISBN 978-0-08-099417-8.

24. Srivastava, A.; Kumar, H.; Singh, S. Investigations into internal surface finishing of titanium (grade 2) pipe with extended magnetic tool. Procedia Manuf. 2018, 26, 181-189. [CrossRef]

25. Davis, J.R. (Ed.) Stainless Steels. In ASM Specialty Handbook; ASM International: Materials Park, OH, USA, 1994; ISBN 978-087170-503-7.

26. Li, W.; Li, X.; Yang, S.; Li, W. A newly developed media for magnetic abrasive finishing process: Material removal behavior and finishing performance. J. Mater. Process. Technol. 2018, 260, 20-29. [CrossRef]

27. Gupta, B.; Jain, A.; Purohit, R.; Rana, R.S.; Gupta, B. Effects of process parameters on the surface finish of flat surfaces in magnetic assist abrasive finishing process. Mater. Today Proc. 2018, 5, 17725-17729. [CrossRef]

28. Singh, L.; Khangura, S.S.; Mishra, P.S. Performance of abrasives used in magnetically assisted finishing: A state of the art review. IJAT 2010, 3, 215. [CrossRef]

29. Gao, Y.; Zhao, Y.; Zhang, G.; Zhang, G.; Yin, F. Polishing of paramagnetic materials using atomized magnetic abrasive powder. Mater. Manuf. Process. 2019, 34, 604-611. [CrossRef]

30. Mulik, R.S.; Pandey, P.M. Magnetic abrasive finishing of hardened AISI 52100 steel. Int. J. Adv. Manuf. Technol. 2011, 55, 501-515. [CrossRef]

31. Yin, C.; Wang, R.; Kim, J.; Lee, S.; Mun, S. Ultra-high-speed magnetic abrasive surface micro-machining of AISI 304 cylindrical bar. Metals 2019, 9, 489. [CrossRef] 